\title{
Adaptive Feedforward Control Design for Gust Loads Alleviation of Highly Flexible Aircraft
}

\author{
Y. Wang* and F. $\mathrm{Li}^{\dagger}$ \\ China Academy of Aerospace Aerodynamics, Beijing, 1000\%4, China \\ A. Da Ronch ${ }^{\ddagger}$ \\ University of Southampton, Southampton, S017 1BJ, United Kingdom
}

\begin{abstract}
When prior knowledge of the plant controlled is available, feedforward control is preferred over feedback control for disturbance rejection. The stability characteristics of the system using feedforward control are the same as the original plant. Adaptive feedforward control design for gust loads alleviation of both a two degrees of freedom aerofoil with polynomial structural nonlinearity and a free flying flexible aircraft with large geometric wing deformations is investigated. Two dimensional thin aerofoil theory based on Theodorsen theory is used to perform aerodynamic analysis in the aerofoil aeroelastic model. The same aerodynamic model coupled with geometrically exact nonlinear beam is used to formulate the multi-disciplinary fluid-structure-flight framework for highly flexible aircraft. Gust loads analysis in terms of both discrete and continuous turbulence gusts are performed based on the aerofoil model and the free flying trim configuration of the highly flexible aircraft. Finite impulse response model is used to design an adaptive feedforward controller to alleviate the gust loads. Adaptive feedforward control shows good gust loads alleviation performance for both discrete and continuous gusts. Compared with adaptive feedback control, it exhibits a greater potential to reduce gust loads from the initial transient of the encounter.
\end{abstract}

\section{Nomenclature}

$\begin{array}{ll}\boldsymbol{A} & \text { Influence matrix between two disciplines } \\ b & \text { Semi-chord } \\ B_{k} & \text { Basis function } \\ C_{\xi}, C_{\alpha} & \text { Viscous damping in plunge and pitch, respectively } \\ \boldsymbol{C}^{B a} & \text { Coordinate transformation matrix from frame } a \text { to frame } B \\ e & \text { Error } \\ F_{l} & \text { Resultant longitudinal force } \\ H, G & \text { Transfer function } \\ H_{g} & \text { Gust gradient } \\ I_{\alpha} & \text { Second moment of inertial of aerofoil about elastic axis } \\ \boldsymbol{k} & \text { Following moment strains or gain vector } \\ K_{\xi}, K_{\alpha} & \text { Plunge stiffness and torsional stiffness about elastic axis } \\ \boldsymbol{K}_{B}, \boldsymbol{R}_{a} & \text { Structure curvature and state } \\ L, M & \text { Lift and pitch moment } \\ \boldsymbol{M}, \boldsymbol{Q} & \text { Mass and gyroscopic or elastic stiffness matrices } \\ L_{k} & \text { Coefficients of basis function } \\ m & \text { Aerofoil sectional mass }\end{array}$

*PhD. Candidate, AIAA Student Member. Email: ywangcasc@yeah.net.

${ }^{\dagger}$ Professor, AIAA Senior Member. Email: caaalifeng@163.com.

${ }^{\ddagger}$ New Frontiers Fellow \& Lecturer, Faculty of Engineering and the Environment, AIAA Member. Email: A.DaRonch@soton.ac.uk. 


\begin{tabular}{|c|c|}
\hline $\mathbf{P}$ & Inverse correlation matrix \\
\hline$r_{a}$ & Radius of gyration of aerofoil about elastic axis \\
\hline $\boldsymbol{R}_{F}$ & Aerodynamic forces \\
\hline$s$ & Arc length \\
\hline$S_{\alpha}$ & First moment of inertial of aerofoil about elastic axis \\
\hline$t$ & Physical time \\
\hline$T$ & Tangential operator \\
\hline$u$ & Input \\
\hline$U_{\infty}$ & Freestream speed \\
\hline $\boldsymbol{v}_{a}, \boldsymbol{w}_{a}$ & Translational and angular velocities in frame $a$ \\
\hline $\boldsymbol{V}_{B}$ & Local translational velocities \\
\hline $\boldsymbol{w}$ & State variables \\
\hline$w_{g}$ & Gust vertical velocity \\
\hline$w_{g 0}$ & Intensity of gust vertical velocity \\
\hline$W$ & Weight \\
\hline$x, y$ & Output \\
\hline$x_{\alpha}$ & Aerofoil static unbalance \\
\hline$z$ & Variable in discrete time system \\
\hline \multicolumn{2}{|l|}{ Greek } \\
\hline$\alpha$ & Angle of attack \\
\hline$\beta_{\xi_{3}}, \beta_{\xi_{5}}, \beta_{\alpha_{3}}, \beta_{\alpha_{5}}$ & Nonlinear spring constants \\
\hline$\gamma$ & Following force strains \\
\hline$\omega_{\xi}, \omega_{\alpha}$ & Uncoupled plunging and pitching mode natural frequency \\
\hline $\bar{\omega}$ & Ratio of $\omega_{\xi} / \omega_{\alpha}$ \\
\hline$\varsigma_{i}$ & Quaternion variables \\
\hline$\varsigma_{\xi}, \varsigma_{\alpha}$ & Damping ratio in plunge and pitch \\
\hline$\xi$ & Nondimensional displacement in plunge \\
\hline$\mu$ & Mass ratio \\
\hline$\varepsilon$ & Cost function \\
\hline$\lambda$ & Forgetting factor \\
\hline$\Omega$ & Scaled frequency \\
\hline$\Omega_{B}$ & Local angular velocities \\
\hline$\Psi$ & Cartesian Rotation Vector \\
\hline \multicolumn{2}{|l|}{ Symbol } \\
\hline$(\bullet)$ & Derivative with respect to $t$ \\
\hline$(\bullet)^{\prime}$ & Derivative with respect to $s$ \\
\hline$(\bullet)$ & Cross product operator \\
\hline$(\hat{\bullet})$ & Approximation \\
\hline
\end{tabular}

\section{Introduction}

High-altitude long-endurance (HALE) aircraft was the research focus for the next generation unmanned aerial vehicle (UAV) platform recently. The solution is usually high aspect ratio with light weight configuration. Because of low wing loading, HALE aircraft is very sensitive to vertical gust. Meanwhile, the frequencies of rigid body motions and aeroelastic vibrations have the tendency to get closer to each other, which increases the nonlinear aeroelastic coupling between flight mechanics and structural dynamics. Thus, atmospheric turbulence gusts significantly excite structural vibrations. These vibrations not only generate dynamic structural loads and influence the rigid body motions of the aircraft, but also cause fatigue issues and reduce the aircraft operational life. Developing a gust-tolerant vehicle through active control is attractive for reduced structural weight HALE aircraft. 
For HALE aircraft, flexibility will lead to large deflection when encountering gust. The mishap of NASA's Helios demonstrated that the traditional (linear) methods are not adequate for the analysis of highly flexible aircraft. ${ }^{1}$ The trim shape of a large flexible aircraft is highly dependent on the flight mission (payload) as well as on the flight condition; the deformed shape is significantly different from the undeformed shape. Thus, the flight dynamic and gust response based on the actual trim shape can be quite different from that calculated based on linear, small deformation assumptions. Furthermore, the linearized model at the nonlinear trim is insufficient if one has to calculate response to large amplitude gust. ${ }^{2}$ Considering the coupling between elasticity and rigid motion, an integrated method of nonlinear aeroelasticity and flight dynamics is essential to perform the gust loads analysis and alleviation for flexible aircraft.

Aircraft active control has been investigated for several decades, especially for flutter suppression, noise reduction, and gust loads alleviation. ${ }^{3,4,5,6,7,8}$ Feedback control strategies, for example, linear quadratic regulator, optimal control algorithm, $\mathrm{H}_{\infty}$ robust control synthesis, are relatively mature and have been used extensively in aeroservoelasticity for gust loads alleviation. When prior knowledge of the disturbance is available, a feedforward control strategy is generally more suitable than feedback control for disturbance rejection. In the most ideal situation, feedforward control can entirely eliminate the effect of the measured disturbance on the process output. Even when there are modeling errors, feedforward control can often reduce the effect of the measured disturbance on the output better than that achievable by feedback control alone. $^{9}$ There is no time delay between the disturbance and control compensation when using feedforward control, which means that corrective action can be taken before the output has deviated from the set point. ${ }^{10}$ It is possible to design a feedforward controller to alleviate gust loads response by measuring the vertical gust speed ahead of aircraft using light detection and ranging (LIDAR) beam airborne wind sensor. ${ }^{10,11,12}$ LIDAR technique has been developing ${ }^{11,13,14}$ and some flight tests have been performed with LIDAR sensor on board. ${ }^{15,16}$ Another new radar system, Honeywells IntuVue 3D weather radar, which can analyze data from 17 different angled "slices" of space at once, showing all of the weather that's in front of the plane, from the ground all the way to 60,000 feet $^{\text {a }}$, is also a promising sensor that can be used for feedforward control.

A linear adaptive feedforward controller was developed by using orthonormal basis function for $\mathrm{F} / \mathrm{A}-$ 18 aircraft gust loads alleviation on linear aeroelastic model and good performances were found. ${ }^{17}$ The environmental requirements in airworthiness regulation for future passenger airliners are extremely strict. To reduce the impact on the environment and improve aircraft global efficiency, a similar solution to the HALE aircraft is needed. ${ }^{18}$ To improve the passenger comfort and handling qualities of a large transport aircraft, an integrated adaptive feedforward controller was designed to alleviate the atmospheric turbulence excited rigid body motions and structural vibrations. The simulation results illustrate the high potential of feedforward control for simultaneous compensation of atmospheric turbulence excited responses. ${ }^{19}$ An adaptive feedforward controller was flight tested to alleviate turbulence excited wing bending vibration. The atmospheric turbulence was obtained by a nose boom mounted flight log sensor. Results show that feedforward compensation of atmospheric turbulence excited wing bending vibrations provides a powerful method for further reduction of dynamic loads and improvement of ride comfort. ${ }^{20}$ Gust loads alleviation and limit cycle oscillations suppression of a two dimensional aerofoil with structural nonlinearity were performed by using adaptive feedforward control (AFFC). The robustness was strengthened by an adaptive strategy. The controller realized by finite impulse response (FIR) filter model shows good performance for alleviating gust loads. ${ }^{21}$

The authors aim at designing an adaptive feedforward controller to alleviate the gust loads response of highly flexible aircraft. This will be accomplished in two phases. The first phase focuses on a 2D aerofoil model. The second phase presents the application to a HALE flexible aircraft configuration. Section II introduces the aerofoil model. The couping framework of flexible aircraft is presented in Section III. Gust models are given in Section IV. Section V describes the AFFC strategy. Examples of aerofoil system and flexible aircraft are shown in Section VI and VII, respectively. Finally, conclusions are given in Section VIII.

\section{Aerofoil Model}

The two dimensional aeroelastic aerofoil model used in this paper, shown in Fig. 1, is a typical aerofoil section with two degrees of freedom (DoF) that define the motion about a reference elastic axis (e.a.). The

\footnotetext{
ahttps://aerospace.honeywell.com/en/products/safety-systems/weather-radar/intuvue-3d-weather-radar, retrieved on 15th April, 2015
} 
plunge deflection is denoted by $h$, positive downward, and $\alpha$ is the angle of attack (AoA) about the elastic axis, positive with nose up. The semi-chord length is $b$. The nondimensional distances from the mid-chord to the elastic axis and from the elastic axis to the centre of gravity are $a_{h}$ and $x_{\alpha}$, respectively. The aerofoil is equipped with a massless trailing-edge flap with hinge at a distance $c b$ from the midchord. The flap deflection, $\delta$, is defined relative to the aerofoil chord.

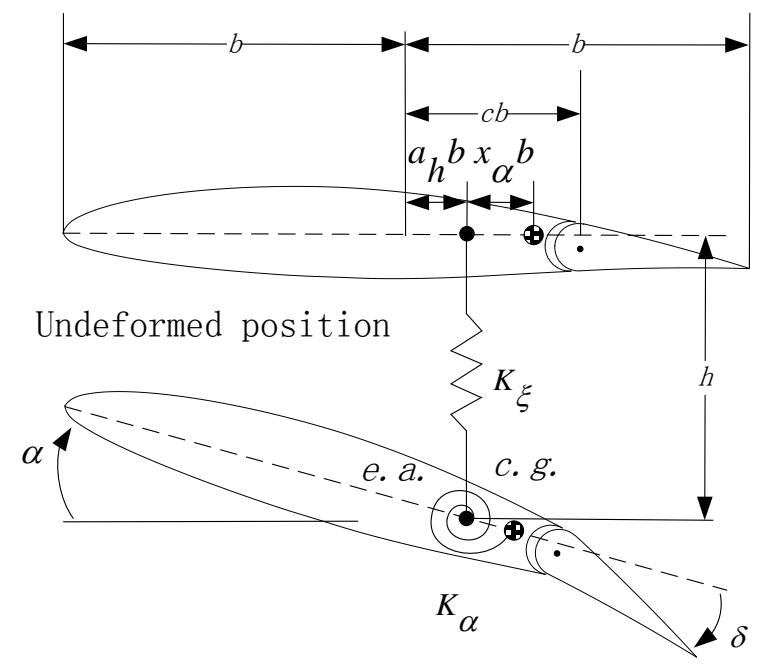

Figure 1: Schematic of an aerofoil section with trailing-edge flap; the wind velocity is to the right and horizontal; e.a. and c.g. denote, respectively, the elastic axis and centre of gravity (CoG)

\section{A. Equation of Motion}

The motion is restrained by two springs, $K_{\xi}$ and $K_{\alpha}$, and the model is assumed to have a horizontal equilibrium position at $h=\alpha=\delta=0$. The system contains structural damping in both pitch and plunge DoF, $C_{\xi}$ and $C_{\alpha}$. The equations in dimensional form with a polynomial nonlinearity for the restoring forces are

$$
\left\{\begin{array}{l}
m \ddot{h}+S_{\alpha} \ddot{\alpha}+C_{\xi} \dot{h}+K_{\xi}\left(h+\beta_{\xi_{3}} h^{3}+\beta_{\xi_{5}} h^{5}\right)=-L \\
S_{\alpha} \ddot{h}+I_{\alpha} \ddot{\alpha}+C_{\alpha} \dot{\alpha}+K_{\alpha}\left(\alpha+\beta_{\alpha_{3}} \alpha^{3}+\beta_{\alpha_{5}} \alpha^{5}\right)=M
\end{array}\right.
$$

where $m, S_{\alpha}$, and $I_{\alpha}$ are the aerofoil sectional mass, the first and second moment of inertia of aerofoil about elastic axis. The lift, $L$, is defined positive upward according to the usual sign convention in aerodynamics. The moment around the elastic axis is $M$. The plunge displacement, $h$, is positive downward, as it is conventionally done in aeroelasticity.

\section{B. Two Dimensional Thin Aerofoil Theory}

To calculate the lift and moment in Eq. (1), the unsteady aerodynamics is modeled with strip theory and the incompressible two-dimensional classical theory of Theodorsen. The model is formulated in first order and contains 12 states. More details can be found in Ref. ${ }^{22}$

\section{Unified Fluid-Structure-Flight Model}

An integrated aerodynamics/structure/flight dynamics coupling framework of highly flexible aircraft is formulated. The aerodynamic model is the same as the aeroelastic aerofoil system, while the structural model is geometrically exact nonlinear displacement-based beam.

\section{A. Geometrically Exact Nonlinear Beam}

The deformation of the structure is described in a Lagrangian manner in terms of a moving, body-fixed reference coordinate system $a$ which moves with respect to an inertial frame $G$. The local orientation of the 
beam cross sections is defined by their local coordinate systems, $B$, in the deformed (or current) configuration. The following force and moment strains at time $t$ with respect to arc length $s$ are

$$
\begin{aligned}
\gamma(s, t) & =\boldsymbol{C}^{B a}(s, t) \boldsymbol{R}_{a}^{\prime}(s, t)-\boldsymbol{C}^{B a}(s, 0) \boldsymbol{R}_{a}^{\prime}(s, 0) \\
\boldsymbol{k}(s, t) & =\boldsymbol{K}_{B}(s, t)-\boldsymbol{K}_{B}(s, 0)
\end{aligned}
$$

where $\boldsymbol{C}^{B a}$ is the coordinate transformation matrix from frame $a$ to $B, \boldsymbol{R}$ is the structural state, $(\bullet)^{\prime}$ denotes the derivative with respect to $s . \boldsymbol{K}_{B}$ is the structural curvature. The local translational and angular inertial velocities are given, respectively, as

$$
\begin{aligned}
& \boldsymbol{V}_{B}(s, t)=\boldsymbol{C}^{B a}(s, t)\left[\dot{\boldsymbol{R}}_{a}(s, t)+\boldsymbol{v}_{a}(t)+\tilde{\boldsymbol{\omega}}_{a}(t) \boldsymbol{R}_{a}(s, t)\right] \\
& \boldsymbol{\Omega}_{B}(s, t)=\boldsymbol{T}(\boldsymbol{\Psi}(s, t)) \dot{\boldsymbol{\Psi}}(s, t)+\boldsymbol{C}^{B a}(s, t) \boldsymbol{\omega}_{a}(t)
\end{aligned}
$$

where $\boldsymbol{v}_{a}$ and $\boldsymbol{\omega}_{a}$ are the translational and rotational velocity with respect to frame $a, \boldsymbol{\Psi}$ is Cartesian Rotation Vector, $(\bullet)$ is the derivative with respect to time $t$ and $(\tilde{\bullet})$ is the cross product operator, and $\boldsymbol{T}(\boldsymbol{\Psi})$ is the tangential operator. ${ }^{23}$

\section{B. Discrete Form of Coupling Equation of Motion}

The nonlinear beam code is coupled with strip aerodynamics. Each structural node has 6 elastic DoF denoted by $\boldsymbol{w}_{\boldsymbol{s}}$. The system rigid body motion is described by 6 DoF $\boldsymbol{w}_{\boldsymbol{r}}$. While 4 quaternions $\boldsymbol{\varsigma}_{i}$ are used to perform the propagation of the beam with respect to the inertial frame. Aerodynamic states are represented by 8 augmented variables for each deformable aerofoil section. The coupling between aerodynamic model and structural model is performed considering that each structural node coincides with an aerodynamic section. No aeroelastic interface is required in this case as the aerodynamic forces and moments are applied directly on each structural node. The discrete form equations of motion of the coupled structure-flight dynamics are written $\mathrm{as}^{24}$

$$
\begin{aligned}
& \boldsymbol{M}\left(\boldsymbol{w}_{s}, \boldsymbol{w}_{r}\right)\left[\begin{array}{c}
\ddot{\boldsymbol{w}}_{s} \\
\ddot{\boldsymbol{w}}_{r}
\end{array}\right]+\boldsymbol{Q}_{\mathrm{gyr}}\left(\dot{\boldsymbol{w}}_{s}, \boldsymbol{w}_{s}, \boldsymbol{w}_{r}\right)\left[\begin{array}{c}
\dot{\boldsymbol{w}}_{s} \\
\dot{\boldsymbol{w}}_{r}
\end{array}\right]+\boldsymbol{Q}_{\mathrm{stiff}}\left(\boldsymbol{w}_{s}\right)\left[\begin{array}{c}
\boldsymbol{w}_{s} \\
\boldsymbol{w}_{r}
\end{array}\right] \\
& =\boldsymbol{R}_{F}\left(\ddot{\boldsymbol{w}}_{s}, \dot{\boldsymbol{w}}_{s}, \boldsymbol{w}_{s}, \ddot{\boldsymbol{w}}_{r}, \dot{\boldsymbol{w}}_{r}, \boldsymbol{w}_{r}, \boldsymbol{w}_{f}, \boldsymbol{\varsigma}_{i}, \boldsymbol{u}_{c}, \boldsymbol{w}_{g}\right) \\
& \dot{\boldsymbol{\zeta}}_{i}+\boldsymbol{C}_{Q R} \dot{\boldsymbol{w}}_{r}+\boldsymbol{C}_{Q Q} \boldsymbol{\varsigma}_{i}=\mathbf{0} \\
& \dot{\boldsymbol{w}}_{f}=\boldsymbol{A}_{f s r}\left[\begin{array}{c}
\boldsymbol{w}_{s} \\
\boldsymbol{w}_{r}
\end{array}\right]+\boldsymbol{A}_{f f} \boldsymbol{w}_{f}+\boldsymbol{A}_{f c} \boldsymbol{u}_{c}+\boldsymbol{A}_{f g} \boldsymbol{w}_{g}
\end{aligned}
$$

where $\boldsymbol{M}, \boldsymbol{Q}_{\mathrm{gyr}}, \boldsymbol{Q}_{\mathrm{stiff}}$, and $\boldsymbol{R}_{F}$ are mass, gyroscopic, elastic stiffness matrices, and aerodynamic forces. The subscripts $s, r, f$ or $F$ denote elastic, rigid-body, aerodynamic properties respectively. The control and gust influence matrices are $\boldsymbol{A}_{f c}$ and $\boldsymbol{A}_{f g}, \boldsymbol{u}_{c}$ is control input and $\boldsymbol{w}_{g}$ is gust velocity. The gyroscopic, elastic matrices, and aerodynamic forces can be discretized into pure elastic, pure rigid body, and their coupling contributions as

$$
\boldsymbol{M}=\left[\begin{array}{ll}
\boldsymbol{M}_{s s} & \boldsymbol{M}_{s r} \\
\boldsymbol{M}_{r s} & \boldsymbol{M}_{r r}
\end{array}\right], \boldsymbol{Q}_{\mathrm{gyr}}=\left[\begin{array}{ll}
\boldsymbol{Q}_{\mathrm{gyr}_{s s}} & \boldsymbol{Q}_{\mathrm{gyr}_{s r}} \\
\boldsymbol{Q}_{\mathrm{gyr}_{r s}} & \boldsymbol{Q}_{\mathrm{gyr}_{r}}
\end{array}\right], \boldsymbol{R}_{F}=\left[\begin{array}{c}
\boldsymbol{R}_{F_{s}} \\
\boldsymbol{R}_{F_{r}}
\end{array}\right]
$$

\section{Trim}

In a trimmed state, the forces and moments acting on aircraft are equal zero. In terms of longitudinal trim, the objective is to find the appropriate combination of AoA, $\alpha$, and elevator deflection, $\delta$ to meet following requirement:

$$
\left[\begin{array}{c}
L-W \\
M
\end{array}\right]=\left[\begin{array}{c}
F_{l}(\alpha, \delta) \\
M(\alpha, \delta)
\end{array}\right]=\left\{\begin{array}{l}
0 \\
0
\end{array}\right\}
$$

where $L$ is the lift, $W$ is the aircraft weight, $M$ is the pitch moment, and $F_{l}$ is the resultant vertical force. Newton-Raphson method is used to find the local minimum of the search variable. Given the $i$ step AoA, $\alpha_{i}$, and elevator deflection $\delta_{i}$, according to Taylor series,

$$
\left[\begin{array}{c}
F_{l} \\
M
\end{array}\right] \approx\left[\begin{array}{c}
F_{l}\left(\alpha_{i}, \delta_{i}\right) \\
M\left(\alpha_{i}, \delta_{i}\right)
\end{array}\right]+\left[\begin{array}{cc}
\frac{\partial F_{l}}{\partial \alpha} & \frac{\partial F_{l}}{\partial \delta} \\
\frac{\partial M}{\partial \alpha} & \frac{\partial M}{\partial \delta}
\end{array}\right]\left[\begin{array}{c}
\Delta \alpha \\
\Delta \delta
\end{array}\right]=\left\{\begin{array}{l}
0 \\
0
\end{array}\right\}
$$


where $\Delta \alpha$ and $\Delta \delta$ are computed by forcing the right side of Eq. (7) to be equal 0 . Then

$$
\left[\begin{array}{c}
\alpha_{i+1} \\
\delta_{i+1}
\end{array}\right]=\left[\begin{array}{c}
\alpha_{i} \\
\delta_{i}
\end{array}\right]+\left[\begin{array}{c}
\Delta \alpha \\
\Delta \delta
\end{array}\right]
$$

Replacing $\alpha_{i}$ and $\delta_{i}$ by $\alpha_{i+1}$ and $\delta_{i+1}$ to continue the trimming process until the prescribed tolerance is satisfied.

\section{Gust Model}

\section{A. Discrete Atmospheric Gust}

The discrete model based on the "one-minus-cosine" shape is formulated as

$$
w_{g}\left(x_{g}\right)=\frac{w_{g 0}}{2}\left(1-\cos \left(\frac{2 \pi x_{g}}{L_{g}}\right)\right), 0 \leq x_{g} \leq L_{g}
$$

where $x_{g}$ is the position of the aircraft in the spatial description of the gust relative to a convenient fixed origin, $w_{g 0}$ is the value of the peak, or intensity of gust velocity and $L_{g}$ is the gust length (or twice the so-called 'gust gradient' $H_{g}$ ). The intensity of gust velocity $w_{g 0}$ varies with gust length, altitude and speed. The "one-minus-cosine" gust is shown in Fig. 2.

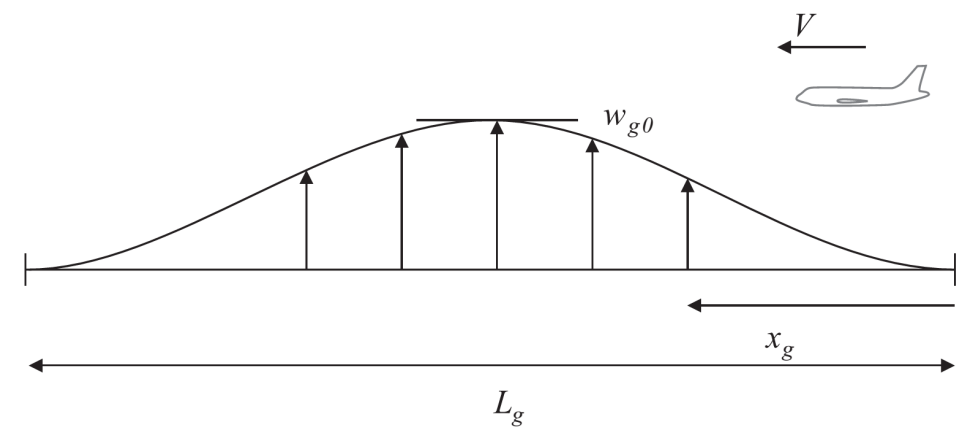

Figure 2: Discrete "one-minus-cosine" gust

\section{B. Continuous Atmospheric Gust}

The Von Kármán spectrum is used to generate the continuous turbulence model. According to the Military Specification MIL-F-8785C, the vertical spectrum function is

$$
\Phi_{z}(\Omega)=\frac{2 \sigma_{z}^{2} L_{z}}{U_{\infty}} \cdot \frac{1+8 / 3\left(1.339 L_{z} \Omega\right)^{2}}{\left[1+\left(1.339 L_{z} \Omega\right)^{2}\right]^{11 / 6}}
$$

where $\Phi_{z}(\Omega)$ is the power spectral density (PSD, in $\mathrm{m}^{2} /\left(\mathrm{s}^{2} \mathrm{~Hz}\right)$ ), $\Omega=\omega / U_{\infty}$ is the scaled frequency (in $\mathrm{rad} / \mathrm{m}$ ), $\sigma_{z}$ is the turbulence intensity (in $\mathrm{m} / \mathrm{s}$ ), $U_{\infty}$ is the freestream speed (in m/s), and $L_{z}$ represents the turbulence scale length (in $\mathrm{m}$ ). The turbulence intensity is

$$
\sigma_{z}=0.1 w_{20}
$$

where $w_{20}$ is the wind speed at altitude $h=20$ feet $(6 \mathrm{~m})$. Typically for light turbulence, the wind speed at 20 feet is 15 knots; for moderate turbulence, the wind speed is 30 knots; and for severe turbulence, the wind speed is 45 knots.

The turbulence is generated by passing a band-limited white noise signal, $X(\Omega)$, through an appropriate forming filter with shape function, $H_{z}(\Omega)$, which is defined as the square root of the power spectral density in Eq. (9). Then, calculate the output signal using the relation

$$
W_{g}(\Omega)=H_{z}(\Omega) X(\Omega)
$$


The continuous atmospheric gust in time domain, $w_{g}(t)$, can be obtained by using the inverse Fourier transform of $W_{g}(\Omega)$. A moderate turbulence spectrum generated at altitude of 20,000 $\mathrm{m}$ and freestream speed of $25 \mathrm{~m} / \mathrm{s}$ are shown in Fig. 3. The red curve was generated by the above method, while the black curve is the exact Von Kármán spectrum. The code is open source ${ }^{\mathrm{b}}$ and is referred to as the Von Kármán Turbulence Generator (VKTG). This gust will be used in the test case for a flexible aircraft. The corresponding time history is given in Fig. 18 later.

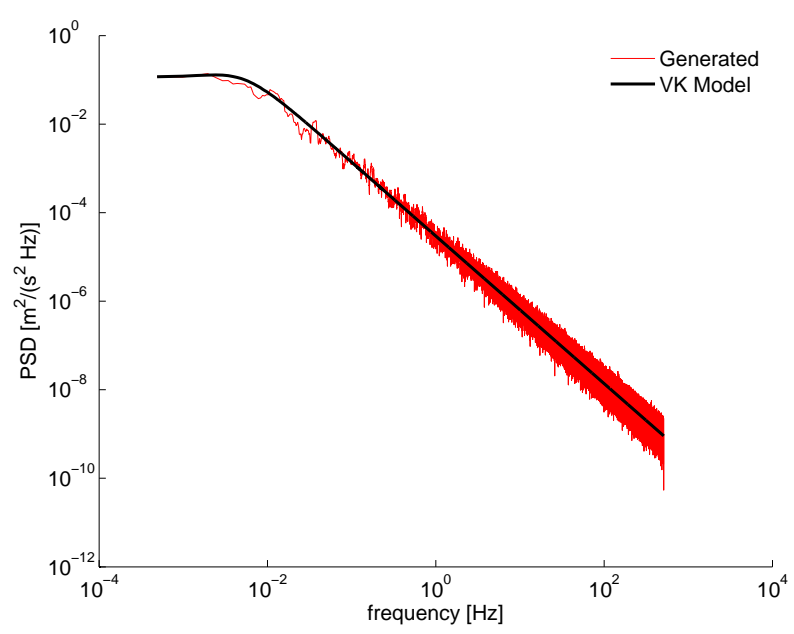

Figure 3: Moderate turbulence spectrum $\left(h=20,000 \mathrm{~m}\right.$, intensity $=10^{-3}$, 'moderate', $\left.U_{\infty}=25 \mathrm{~m} / \mathrm{s}\right)$; for time history, see Fig. 18

\section{Adaptive Feedforward Control}

A feedforward control system consists of two channels, shown in Fig. 4. One channel is the disturbance path and the other one is the control path. Here, denote $w_{g}$ the atmospheric gust disturbance, which is one direction component of $\boldsymbol{w}_{g}$ used in Sec. III, and by $\hat{w}_{g}$ the gust measured by the on-board LIDAR or other type of sensors. In this paper, it is assumed that the measured gust, $\hat{w}_{g}$ from an "ideal" LIDAR, is identical to the true atmospheric gust, $w_{g}$, and $w_{g}$ will be used in the remaining of the paper. The transfer function of the physical plant (in this case, the aerofoil section or HALE aircraft) between the gust disturbance and the structural response (e.g., pitch or plunge), $x$, is denoted by $H$. $G$ indicates the transfer function of the physical plant between the control effector (in this case, the trailing edge flap of the aerofoil or the aileron or the elevator of the HALE aircraft) and the structural response, and $\hat{G}$ indicates the approximate transfer function of $-G$. The feedforward controller is represented by $G_{c}$, and $u(t)$ indicates the controller output, e.g. the rotation of the trailing edge flap. The object of this study is to design the feedforward controller $G_{c}$ to control the gust response of the nonlinear aerofoil model or HALE aircraft. Theoretically, the ideal feedforward controller $G_{c_{i}}$ is

$$
G_{c_{i}}=-H G^{-1}
$$

but in practice, it is difficult to get the exact transfer function of the physical plant.

The method used to evaluate the transfer function is usually based on system identification. The input excitation signal and the corresponding output response can be either measured from tests or predicted from simulation. To get a good approximation that can capture the most important characteristics of the system, the input signal needs to have an adequate frequency band to ensure that the system is fully excited.

First, the approximation transfer function between the control effector input, $u(t)$, and the system response, $y(t)$, in the control path, $\hat{G}$ is identified

$$
\hat{G} \approx-G
$$

Then, using $\hat{G}$ to filter the measured gust signal $w_{g}(t)$, allocate the output response, $u_{a}(t)$,

\footnotetext{
${ }^{b}$ www.personal.soton.ac.uk/adr1d12
} 


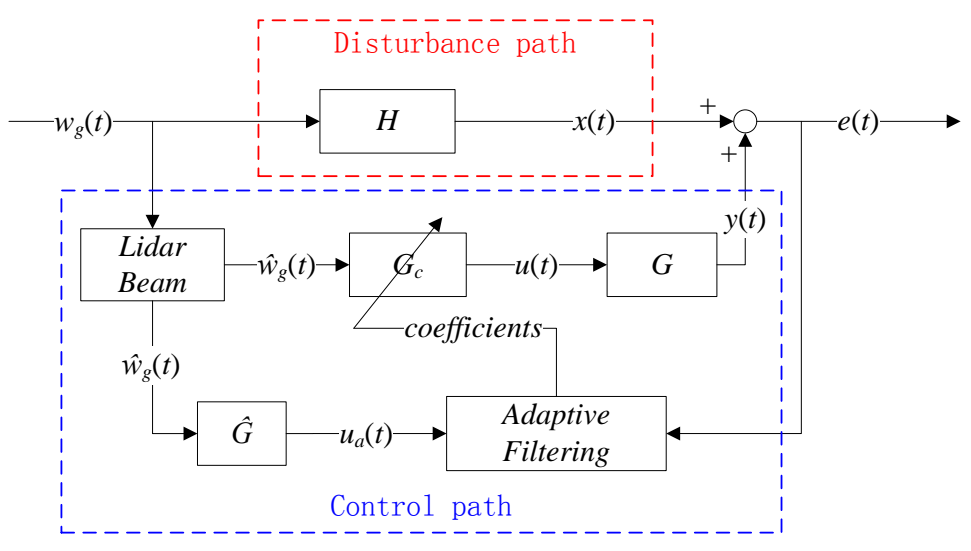

Figure 4: Block diagram of the adaptive feedforward control applied to a physical plant with transfer function $H ; G$ and $G_{c}$ denote, respectively, the transfer function between the input of control surface and the response of the plant and the controller; $\hat{G}$ is an approximation of $-G$; the part in red dashed curve is disturbance path; the part in blue dashed curve is control path

$$
u_{a}(t)=\hat{G} w_{g}(t)
$$

In the disturbance path, the relationship of response $x(t)$ and gust $w_{g}(t)$ is

$$
x(t)=H w_{g}(t)
$$

Substituting Eq. (13) and Eq. (14) into Eq. (15) yields

$$
x(t) \approx-H G^{-1} u_{a}(t)
$$

The a priori information about the physical system for feedforward control can be identified by using $u_{a}(t)$ as input and $x(t)$ as output. ${ }^{21}$ In a controlled system, $x(t)$ is replaced by system response $e(t)$ compensated by the feedforward controller, which is the error between the disturbance response $x(t)$ and the control path response $y(t)$. The combination response of system $e(t)$ can be obtained by a sensor in practice.

Once the above models of the physical plant to be controlled are available, adaptive strategy can be used to ensure the robustness of the feedforward controller. The coefficients of the controller are computed by an adaptive filtering algorithm.

The controller is considered as a discrete linear time invariant system

$$
u(t)=G_{c}(q) w_{g}(t)
$$

where $w_{g}(t)$ is the input signal and $u(t)$ is the corresponding output signal. $G_{c}(q)$ is the transfer operator representing the controller, where $q$ is the forward shift operator, $q w_{g}(t)=w_{g}(t+1)$, and $q^{-1}$ is the delay (backward shift) operator, $q^{-1} w_{g}(t)=w_{g}(t-1)$. The corresponding transfer function $G_{c}(z), z \in \mathbb{C}$, which is formulated as

$$
G_{c}(z)=\sum_{k=1}^{n} L_{k} B_{k}(z)
$$

where $B_{k}(z)$ are basis functions, $L_{k}$ are the corresponding coefficients, and $n$ is the model order. In this paper, finite impulse response model is used as basis function to approximate the ideal feedforward controller.

\section{A. Finite Impulse Response Model}

A FIR model of Eq. (18) corresponds to the choice

$$
B_{k}(z)=z^{-k}, k=1,2, \ldots, n
$$

where $n$ is the order of model chosen by the balance of the approximation accuracy and computational cost. The FIR model structure is shown in Fig. 5. So the FIR model means using a number of transfer functions with zero poles to approximate the controller. 


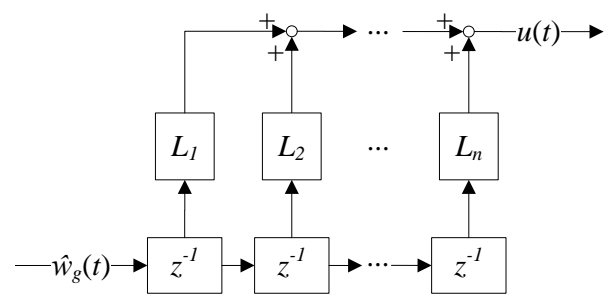

Figure 5: Structure of FIR model to form the controller transfer function, Eq. (19)

\section{B. Exponentially Weighted Recursive Least-square Algorithm}

The coefficients of the basis functions $L_{k}$ in Eq. (19) are calculated by exponentially weighted recursive least-square algorithm. Denote a cost function by

$$
\begin{gathered}
\varepsilon(N)=\sum_{i=1}^{N} \lambda^{N-i}|\hat{e}(i)|^{2} \\
0<\lambda \leq 1, N=1,2, \ldots
\end{gathered}
$$

where $N$ is the total number of time steps, $\lambda$ is the forgetting factor $(\lambda \in[0,1]$ for example), and $\hat{e}(i)$ is the error between the desired response $e(i)$ and the FIR model output $r(i)$ at time $i$

$$
\hat{e}(i)=e(i)-r(i)=e(i)-\boldsymbol{L}^{T}(N) \boldsymbol{\Phi}(i)
$$

the vector $\boldsymbol{\Phi}(i)=\left[u_{a_{1}}(i), u_{a_{2}}(i), \ldots, u_{a_{n}}(i)\right]$ is the output of every basis function of the FIR model, and $\boldsymbol{L}(N)=\left[L_{1}(N), L_{2}(N), \ldots, L_{n}(N)\right]$ is the corresponding coefficient vector, or called tap weight vector. The adaptive algorithm includes the following steps:

- Initialize

$\boldsymbol{L}(0)=\mathbf{0}$,

$\mathbf{P}(0)=\delta^{-1} \mathbf{I}$, where $\delta$ is a small positive constant (e.g. 1).

- Iterate for each instant of time, $N=1,2, \ldots$, compute

$$
\begin{aligned}
\boldsymbol{\pi}(N) & =\mathbf{P}(N-1) \boldsymbol{\Phi}(N) \\
\boldsymbol{k}(N) & =\frac{\boldsymbol{\pi}(N)}{\lambda+\boldsymbol{\Phi}^{T}(N) \boldsymbol{\pi}(N)} \\
\varepsilon(N) & =e(N)-\boldsymbol{L}^{T}(N-1) \boldsymbol{\Phi}(N) \\
\boldsymbol{L}(N) & =\boldsymbol{L}(N-1)+\boldsymbol{k}(N) \bar{\varepsilon}(N) \\
\mathbf{P}(N) & =\lambda^{-1} \mathbf{P}(N-1)-\lambda^{-1} \boldsymbol{k}(N) \boldsymbol{\Phi}^{T}(N) \mathbf{P}(N-1)
\end{aligned}
$$

where $\mathbf{P}(N)$ is the inverse correlation matrix, $\boldsymbol{k}(N)$ is a gain vector, and $\boldsymbol{\pi}(N)$ is a middle variable which is used to increase the computation accuracy. The forgetting factor $\lambda$ should be carefully chosen. By default, the value 1.0 is used. More details about this algorithm can be found in Ref. ${ }^{25}$

\section{Control Path Identification}

A chirp signal is used as the control surface (e.g. the flap of the aerofoil or the ailerons of the aircraft) input to identify the transfer function of the control path. The signal has the following form

$$
u(t)=u_{0}+u_{A} \sin (2 \pi f t)
$$

where $u_{0}$ is a constant input, $u_{A}$ is the amplitude of input signal. The instantaneous frequency $f$ at time $t$ is

$$
f=f_{0} t
$$

where $f_{0}$ is a constant value. An appropriate choice of $f$ ensures covering the frequency range of interest.

$$
9 \text { of } 22
$$




\section{Control Law}

The system controlled in this paper is deemed as a single input single output (SISO) system. Two different control laws are designed in terms of 2D aeroelastic system and 3D flexible aircraft, respectively.

\section{1. $\alpha$-law}

The 2D aeroelastic system has two DoF, pitch and plunge. The $\alpha$-law means that the control objective is mainly to reduce the pitch response when encountering gust, while to expect that the influence to plunge response is small in terms of the control operation. For this $2 \mathrm{D}$ aerofoil system, the pitch response reflects the torque moment, while the plunge response is corresponding to the bending moment. When using $\alpha$ law, the torque moment is alleviated when reducing the AoA through the control operation. Meanwhile, the lift coefficient part dependent on the AoA of the aerofoil is decreased because of the AoA reduction, which will also reduce the impact of gust on plunge response.

\section{2. $a_{z}-$ law}

The task of gust loads alleviation for flexible aircraft is to reduce the wing bending moment. The acceleration of the wing relative to the center of gravity of the aircraft is defined as $a_{z}$-law, which actually gives the measure of wing bending induced by gust. ${ }^{26}$ Three accelerometers are installed on the left and the right wing tip and the CoG, respectively. The values of measurement are denoted as $a_{z \text { left }}, a_{z \mathrm{right}}$, and $a_{z \mathrm{CoG}}$. Then

$$
a_{z}=\frac{a_{z \mathrm{left}}+a_{z \mathrm{right}}}{2}-a_{z \mathrm{CoG}}
$$

The advantage of choosing Eq. (25) is that the rigid body dynamics can be partly removed, while the vertical wing bending is still observed. ${ }^{1}$

\section{Aerofoil Results}

The 2D aeroelastic system has been already validated by wind tunnel test. ${ }^{21}$ More comparisons between aeroelastic model and experiment can be found in Ref. ${ }^{22}$ For completeness, the aeroelastic parameters are briefly summarized in Table 1 . The wind tunnel aeroelastic model has the following parameters which were measured at the University of Liverpool: wing semi-chord $b=0.175 \mathrm{~m}$, pitch circular frequency $\omega_{\alpha}=28.061$ $\mathrm{rad} / \mathrm{s}$, plunge circular frequency $\omega_{\xi}=16.629 \mathrm{rad} / \mathrm{s}$. The freestream speed $U_{\infty}$ used in the following cases is $8 \mathrm{~m} / \mathrm{s}$.

Table 1: Aerofoil parameters

\begin{tabular}{ll}
\hline \hline Parameter & Value \\
\hline $\bar{\omega}$ & 0.593 \\
$\mu$ & 69.000 \\
$a_{h}$ & -0.333 \\
$x_{\alpha}$ & 0.090 \\
$r_{a}$ & 0.400 \\
$\zeta_{\alpha}$ & 0.015 \\
$\zeta_{\xi}$ & 0.015 \\
$\beta_{\xi_{3}}$ & 1741.881 \\
$\beta_{\xi_{5}}$ & 638721.901 \\
\hline \hline
\end{tabular}

\section{A. Control Path Identification}

Chirp signal is used as flap input to excite the aerofoil. The frequency $f$ changes from 0.01 to $8 \mathrm{~Hz}$, which covers both the pitch and plunge frequency. The total simulation time is $21.875 \mathrm{~s}$. Its initial value $u_{0}$ and 
amplitude $u_{A}$ are 0 and 2 degree, respectively. Figure 6 shows the aerofoil responses in terms of chirp signal. The figure shows that both the pitch and plunge modes are fully excited.

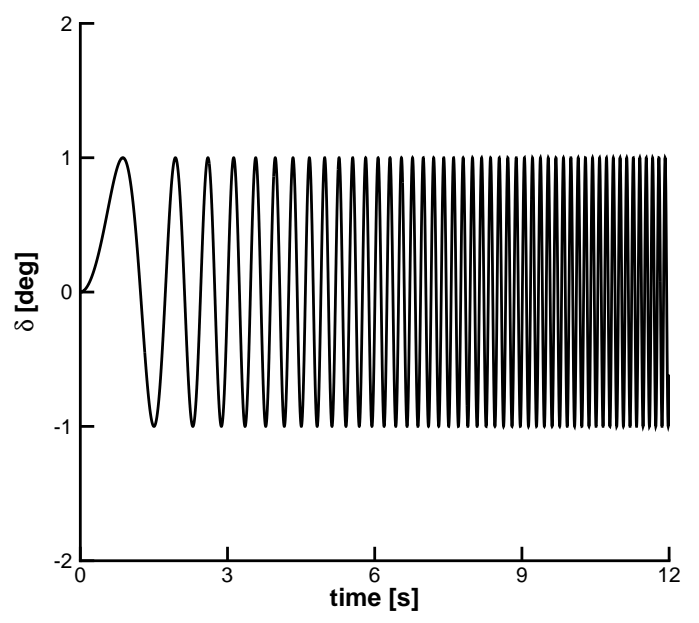

(a) Flap deflection

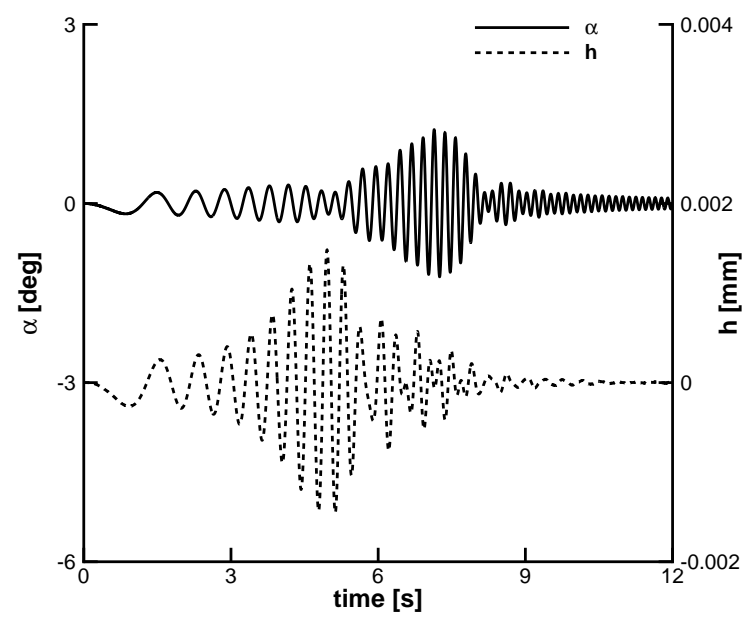

(b) Pitch and plunge response

Figure 6: Chirp input of flap and the corresponding pitch and plunge response

The pitch response in time domain and its corresponding input are used to identify the transfer function of the control path. The identification results by using prediction error minimization (PEM) approach with 6 zeros and 7 poles are shown in Fig. 7. The zeros and poles are listed in Table 2. All the real part of the poles are negative, so the transfer function identified is stable. In Fig. 7a, the solid line and the dashed line (using "Identification" in the legend) are Bode plots of the exact and identified transfer function, respectively. The two peak values are corresponding to the pitch and plunge mode, respectively. This can also be found in time domain response of Fig. 6b. Figure 7b shows the system pitch response and the response obtained from the identified transfer function. The identified transfer function agrees well with the exact one. It will be used as the approximation transfer function $\hat{G}$ to filter the gust.
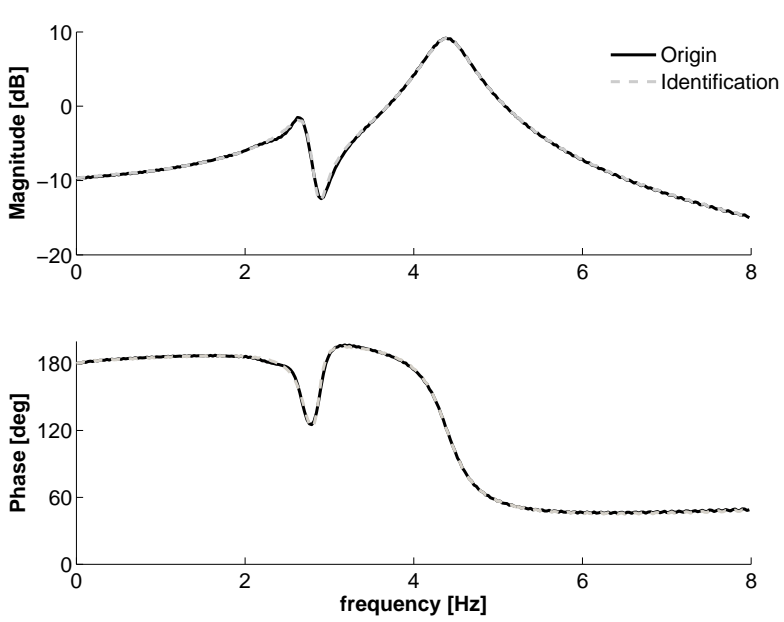

(a) Frequency domain

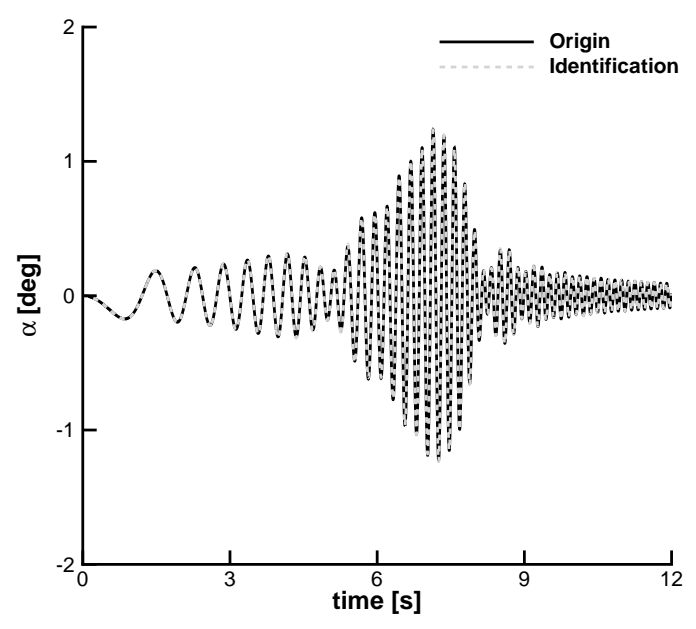

(b) Time domain

Figure 7: The identification results of pitch response: (a) Bode plot, (b) response in time domain 
Table 2: Zeros and poles of the identified transfer function for the pitch response of aerofoil

\begin{tabular}{ll}
\hline \hline Zeros & Poles \\
\hline$-1.492 \pm 1.273 i$ & $-0.037 \pm 0.604 i$ \\
$-0.010 \pm 0.394 i$ & $-0.018 \pm 0.376 i$ \\
-0.523 & -3.982 \\
-0.035 & -0.716 \\
& -0.037 \\
\hline \hline
\end{tabular}

\section{B. Gust Loads Alleviation by Using AFFC}

"One-minus-cosine" gust and Von Kármán turbulence gust with medium intensity of 0.1 (based on the system responses) are investigated to verify the control approach in cases where the structural nonlinearity strongly affects the system responses.

1. "One-minus-cosine" Gust

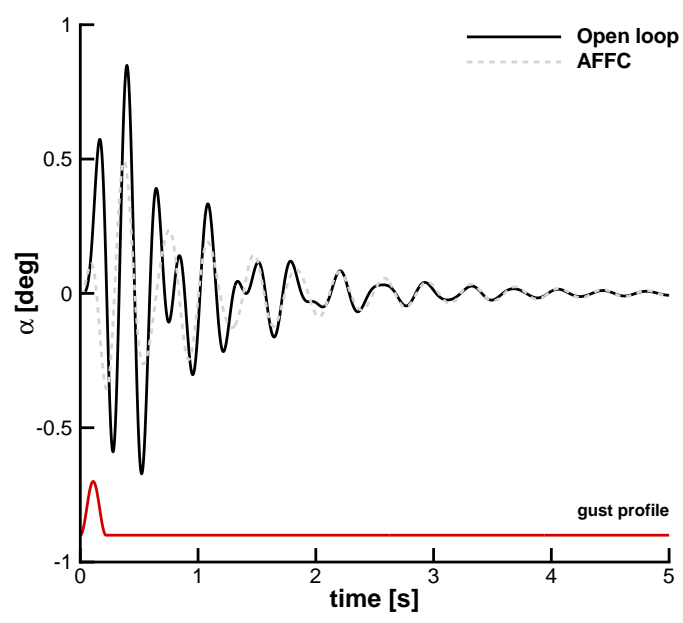

(a) Pitch

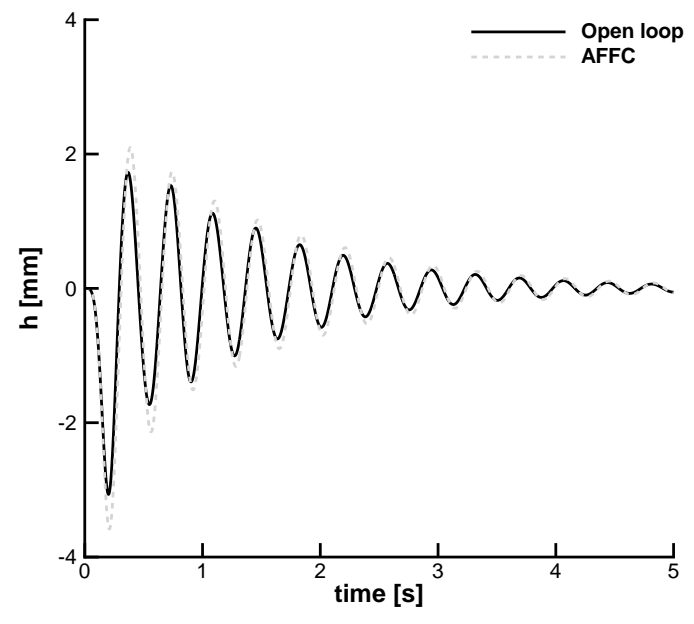

(b) Plunge

Figure 8: Open loop and control responses to a "one-minus-cosine" gust $\left(w_{g 0}=0.8 \mathrm{~m} / \mathrm{s}, L_{g}=1.75 \mathrm{~m}\right.$, $\left.U_{\infty}=8 \mathrm{~m} / \mathrm{s}\right)$

The open loop and control responses to "one-minus-cosine" gust with intensity of 0.1 and wavelength of 10 semi-chords (worst case for pitch mode by worst-case-gust search from wave length of 5 to 100 semichords) are shown in Fig. 8. The AFFC controller shows effective gust loads alleviation for pitch at the initial several cycles. The first peak value is reduced by more than $50 \%$. The alleviation impact is decreasing because after one gust cycle there is no effective reference input for the control path. A small value of the plunge response magnitude is increased because of the flap operation. The reason is because the $\alpha$-law is used here. The adaptive feedforward controller is a single input single output controller. It was designed to just alleviate the pitch response. The flap rotation is shown in Fig. 9a. For the wind tunnel rig, the flap rotation range is \pm 7 degree. All the values in Fig. 9 are located in the maximum limitation of flap. The corresponding angular speed of flap is also smaller than the practical experimental limit $15 \mathrm{~Hz}$. The flap also just works around one gust cycle. The higher order of the FIR AFFC controller, the higher control efficiency. But the computational cost will also be increased. Through convergence and trade-off study, here the order of 20 is chosen. The initial coefficients of the controller were trained by 10,000 steps of Von 


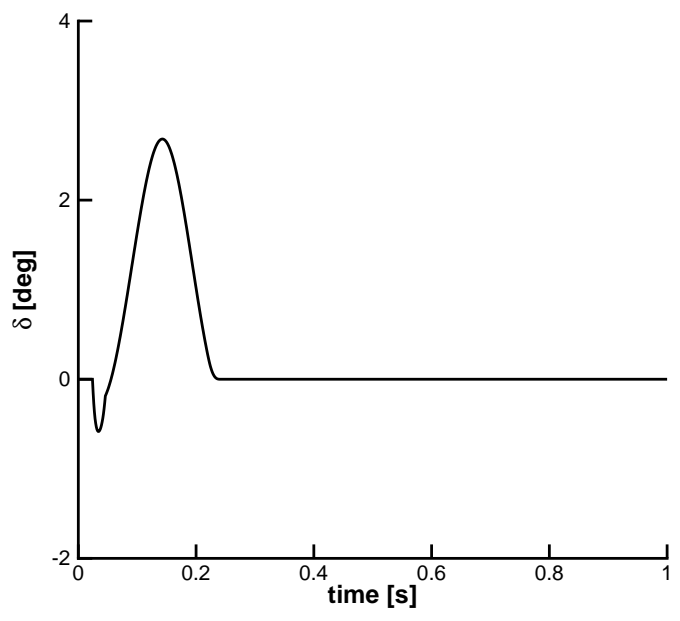

(a) Flap rotation

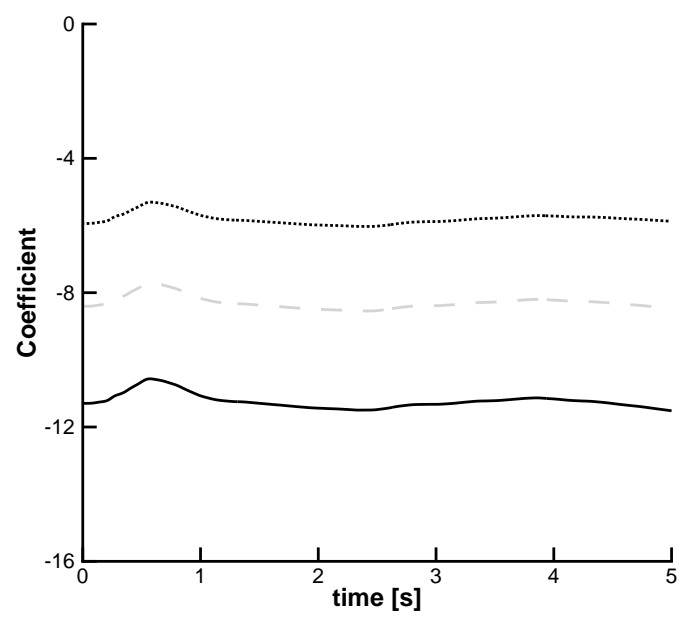

(b) Coefficients

Figure 9: Flap rotation and three coefficients of the controller

Kármán turbulence gust control. Three of them are shown in Fig. 9b.

\section{Von Kármán Turbulence Gust}

A moderate Von Kármán turbulence gust in vertical direction at altitude of $200 \mathrm{~m}$ and freestream speed of $8 \mathrm{~m} / \mathrm{s}$ was generated by VKTG code. The time history of this gust are shown in Fig. 10. The $\alpha$-law is still used here to reduce the pitch response. Figure 11 shows the open loop and control responses to this Von Kármán turbulence gust by using AFFC controller. The mean value and standard deviation of the responses are given in Table 3.

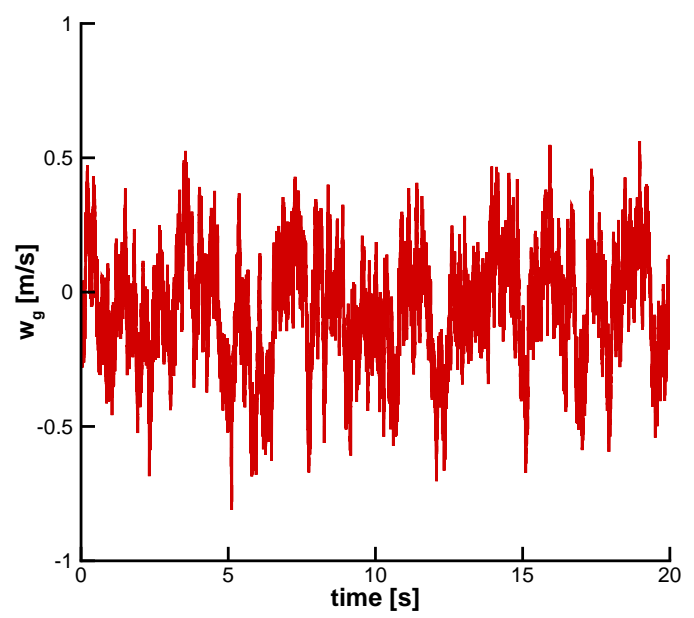

Figure 10: A Von Kármán gust $\left(h=200 \mathrm{~m}\right.$, intensity $=10^{-3}$, 'moderate', $\left.U_{\infty}=8 \mathrm{~m} / \mathrm{s}\right)$ with peak value of $0.8 \mathrm{~m} / \mathrm{s}$

The AFFC controller has effective control on the Von Kármán continuous gust for pitch, while small difference is found for plunge between open loop and control responses. The standard deviation of pitch response is reduced from $0.2361 \mathrm{deg}$ to $0.1495 \mathrm{deg}$ by $36.7 \%$. Meanwhile the mean value of pitch response 


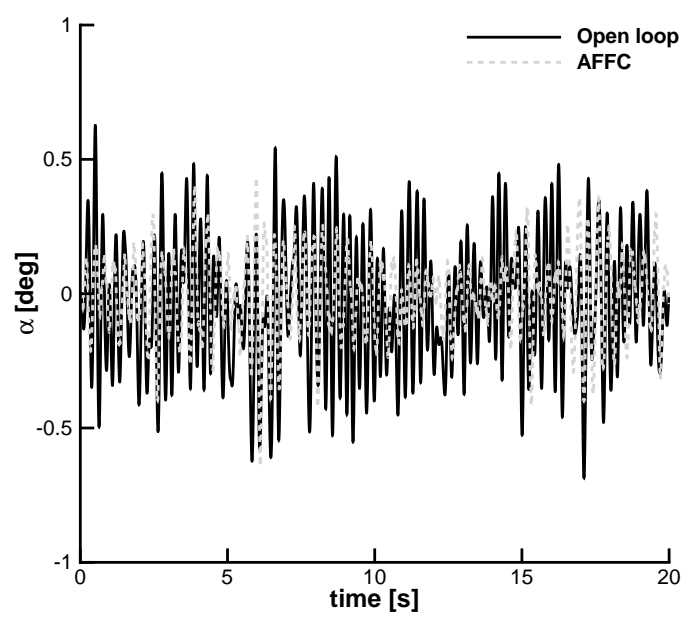

(a) Pitch

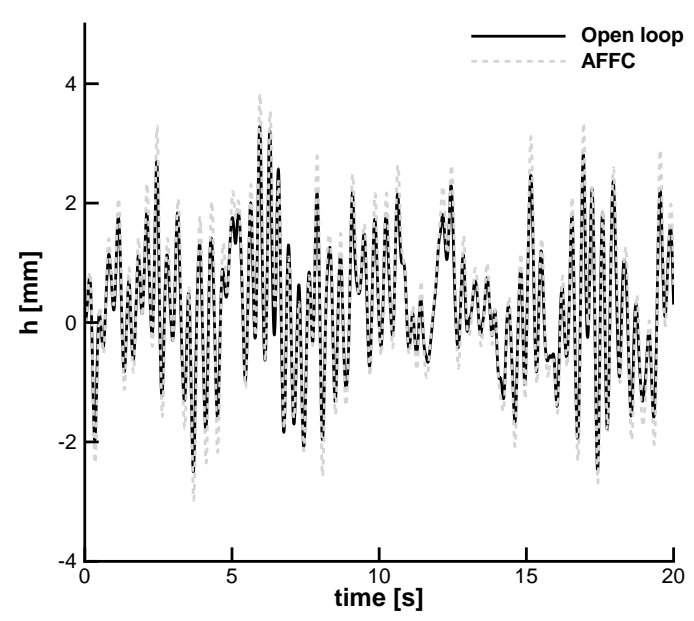

(b) Plunge

Figure 11: Open loop and controlled responses to a Von Kármán gust $\left(h=200 \mathrm{~m}\right.$, intensity $=10^{-3}$, 'moderate', $U_{\infty}=8 \mathrm{~m} / \mathrm{s}$ ) with peak value of $0.8 \mathrm{~m} / \mathrm{s}$

Table 3: The mean value and standard deviation of pitch and plunge responses

\begin{tabular}{lllll}
\hline \hline & \multicolumn{2}{c}{ Pitch [deg] } & \multicolumn{2}{c}{ Plunge [mm] } \\
& Open loop & AFFC & Open loop & AFFC \\
\hline Mean value & -0.0389 & -0.0085 & 0.0015 & 0.0018 \\
Standard deviation & 0.2361 & 0.1495 & 0.0060 & 0.0072 \\
\hline \hline
\end{tabular}

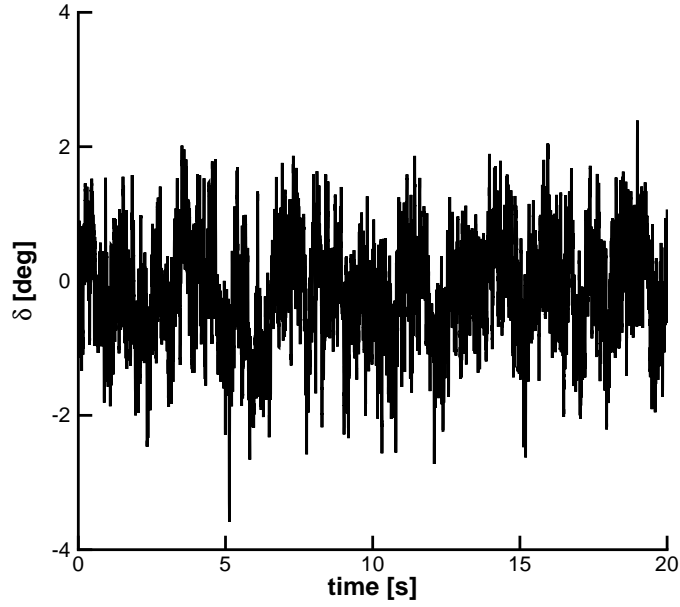

(a) Flap deflection

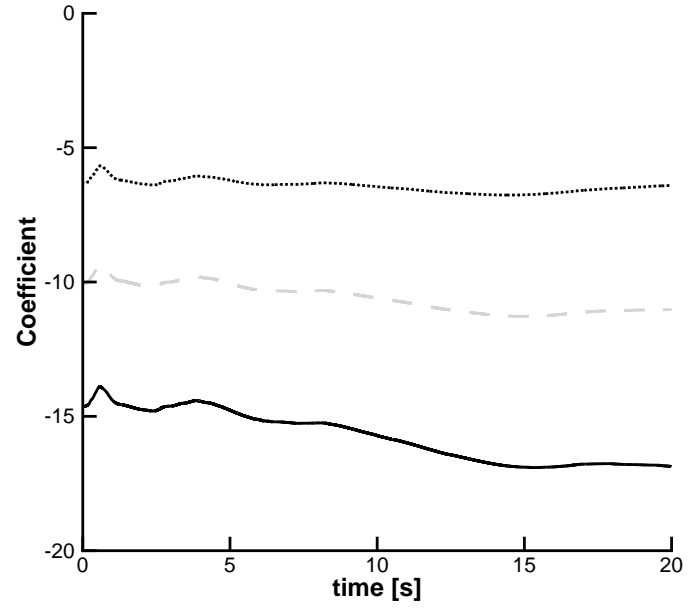

(b) Coefficients

Figure 12: Flap deflection and three coefficients of the controller 
is reduced by $78.1 \%$. The standard deviation and mean value of plunge response are both increased by $20 \%$. The reduction of the amplitude and mean value of the pitch response will decrease the gust impact on aircraft fatigue and extend the operation life. The flap rotation of the AFFC controller shown in Fig. 12a is within the experimental setting limits. The initial values of the controller coefficients were trained by 10,000 steps Von Kármán Turbulence gust. Three of the coefficients are shown in Fig. 12b.

\section{Flexible Aircraft Results}

The AFFC approach is tested on the HALE flexible aircraft to alleviate gust loads. The $a_{z}$-law for this $3 \mathrm{D}$ case is used. The HALE configuration is shown in Fig. 13. The previous papers from the authors have been looking at different aspects of this class aircraft (or a fixed wing), including dynamic response, ${ }^{27}$ control, ${ }^{8,24}$ and model order reduction. ${ }^{18}$ Hence, the present paper will build upon the previous results.
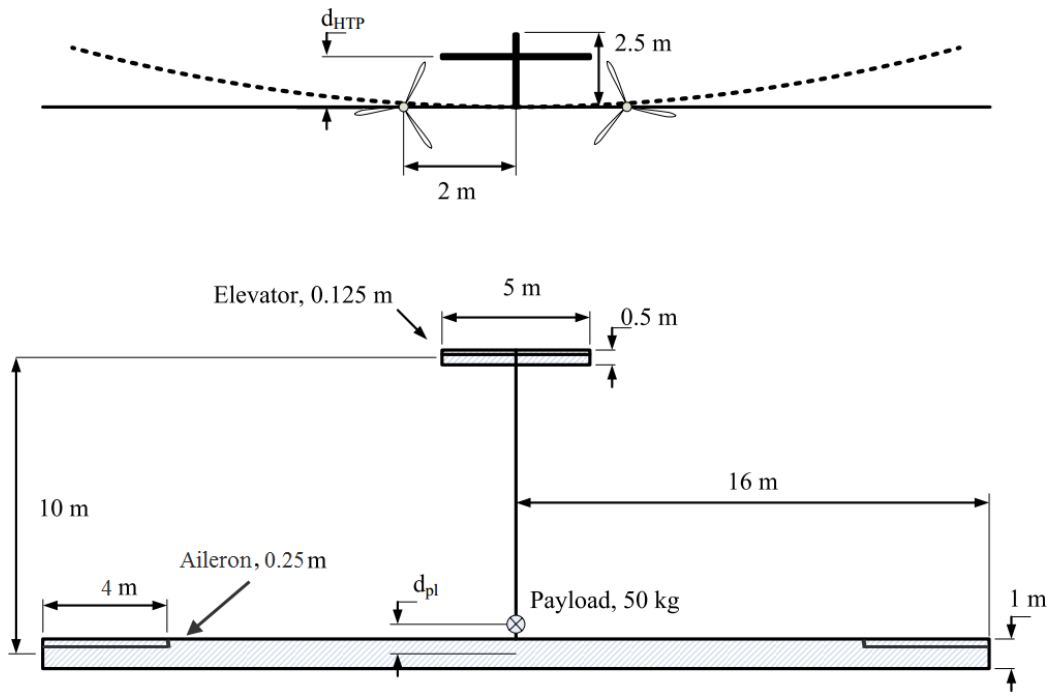

Figure 13: HALE model aircraft geometry ${ }^{28}$

Table 4: Aircraft parameters and structure properties ${ }^{24}$

\begin{tabular}{llll}
\hline \hline Parameter & Main wing & HTP & VTP \\
\hline Chord $[\mathrm{m}]$ & 1.0 & 0.5 & 0.5 \\
Semi-span $[\mathrm{m}]$ & 16.0 & 2.5 & 2.5 \\
Elastic-axis & $50 \%$ chord & $50 \%$ chord & $50 \%$ chord \\
CoG & $50 \%$ chord & $50 \%$ chord & $50 \%$ chord \\
Mass per unit length $[\mathrm{Kg} / \mathrm{m}]$ & 0.75 & 0.08 & 0.08 \\
Moment of inertial $[\mathrm{Kg} \cdot \mathrm{m}]$ & 0.1 & 0.01 & 0.01 \\
Torsional stiffness $\left[\mathrm{N} . \mathrm{m}^{2}\right]$ & $\sigma_{1} \times 10^{4}$ & $\infty$ & $\infty$ \\
Bending stiffness $\left[\mathrm{N} . \mathrm{m}^{2}\right]$ & $2 \sigma_{1} \times 10^{4}$ & $\infty$ & $\infty$ \\
Chordwise bending stiffness $\left[\mathrm{N} . \mathrm{m}^{2}\right]$ & $\sigma_{2} \times 10^{6}$ & $\infty$ & $\infty$ \\
\hline \hline
\end{tabular}

\section{A. Validation}

Rigid aircraft trim at altitude of $20,000 \mathrm{~m}$ is performed to validate the coupling framework. The results by using strip theory compared with unsteady vortex lattice method (UVLM) ${ }^{28}$ are shown in Fig. 14. The trim results of the two methods are very close. Differences become smaller at higher speed when the AoA is also smaller. This is due to three dimensional flow effect decreases at lower AoA. Strip theory uses two 
dimensional flow assumption, while UVLM can consider three dimensional flow effect. More validations about flexible aircraft can be found in Ref. ${ }^{24}$

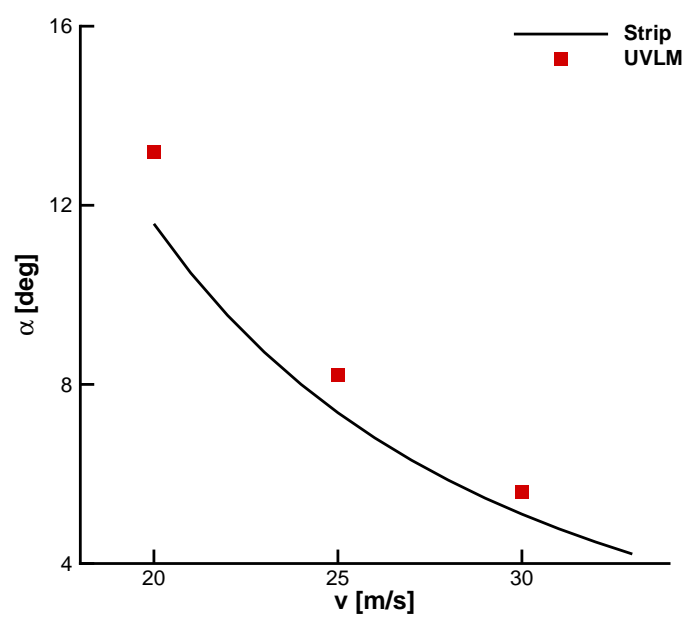

(a) AoA

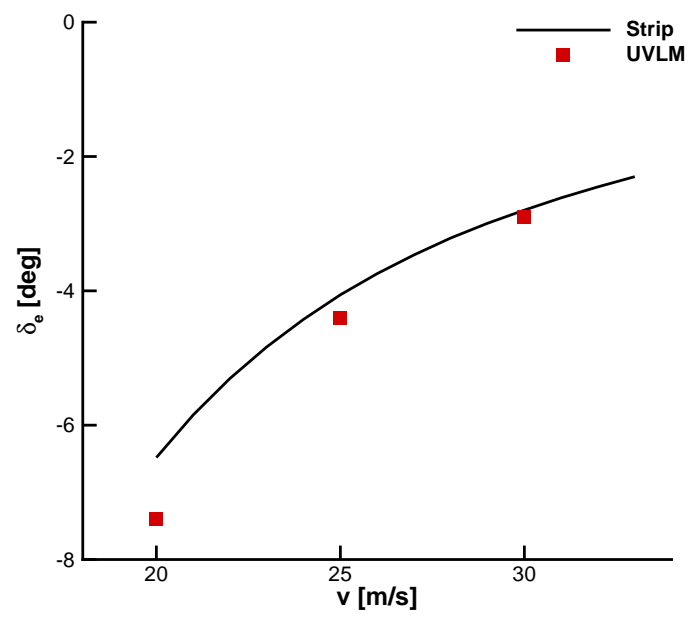

(b) Elevator deflection

Figure 14: AoA and elevator deflection of trimmed rigid aircraft, $\mathrm{d}_{p l}=0$

\section{B. Trim of flexible aircraft}

From here, considering aircraft structure in practice, the elastic axis and the CoG are moved from $50 \%$ to $25 \%$ of the chord for wing, HTP, and VTP. Flexible aircraft trim is done at altitude of 20,000 m. Some other parameters are shown in Table 5 . The trim results are given in Table 6 . The trim state at speed of $25 \mathrm{~m} / \mathrm{s}$ is prescribed as a starting point in the following part. All the dynamic responses will base on this initial baseline.

Table 5: Structure property parameters and flight conditions

\begin{tabular}{ll}
\hline \hline Parameter & Value \\
\hline$\sigma_{1}$ & 1.0 \\
$\sigma_{2}$ & 4.0 \\
$h[\mathrm{~m}]$ & 20,000 \\
$\rho\left[\mathrm{kg} / \mathrm{m}^{3}\right]$ & 0.0089 \\
\hline \hline
\end{tabular}

Table 6: Trimming characteristics and wing tip deflection

\begin{tabular}{llll}
\hline \hline $\boldsymbol{v}[\mathrm{m} / \mathrm{s}]$ & $\alpha[\mathrm{deg}]$ & $\delta_{e}[\mathrm{deg}]$ & Tip deflection $[\mathrm{m}]$ \\
\hline 25 & 12.65 & -30.98 & 8.97 \\
30 & 8.00 & -16.44 & 8.48 \\
\hline \hline
\end{tabular}

\section{Control Path Identification}

Two ailerons are installed on the tip of left and right wing to alleviate the gust loads on wing (see Fig. 13). The dimension is $4 \mathrm{~m} \times 0.25 \mathrm{~m}$. The $a_{z}$-law is used to evaluate the gust loads alleviation effect on the flexible aircraft. The elevator is fixed at the trim state in this case. Firstly, the transfer function of the control path 
needs to be identified. The approach is the same as the one used in the aerofoil case. The aircraft is excited by the ailerons using chirp signal as input. Both the left and right ailerons deflects up and down in the same time in symmetric way. The frequency range of the chirp signal is changing from 0.01 to $5 \mathrm{~Hz}$, which is enough to cover several low order natural frequencies of the structure. Its initial value $u_{0}$ and amplitude $u_{A}$ are 0 and 4 degree, respectively. Figure 15 presents the aircraft AoA and wing tip deflection dynamic responses with respect to the aileron chirp input. PEM approach is used to identify the transfer function of control path through the time domain response of the wing tip acceleration. The identification results by using 10 poles and 9 zeros are given in Fig. 16. Both the frequency and time domain results show that the transfer function identified agrees well with the original one. All the real part of the poles are negative. Their values are omitted here.

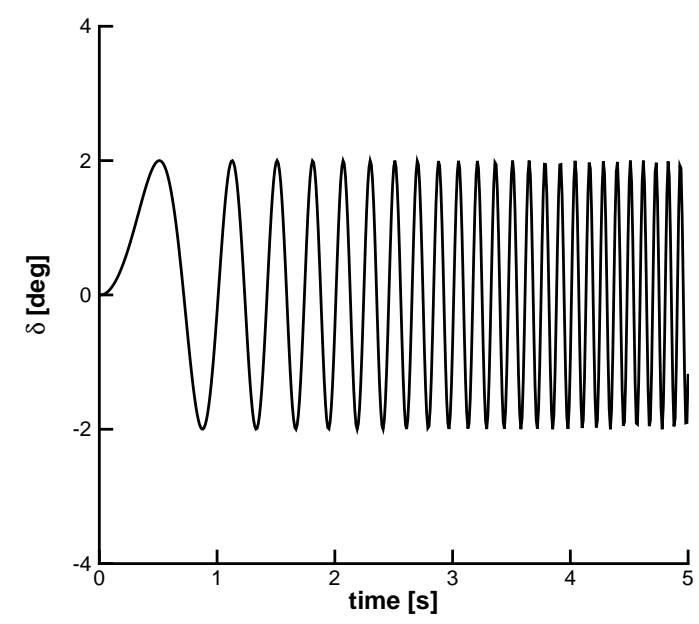

(a) Aileron deflection

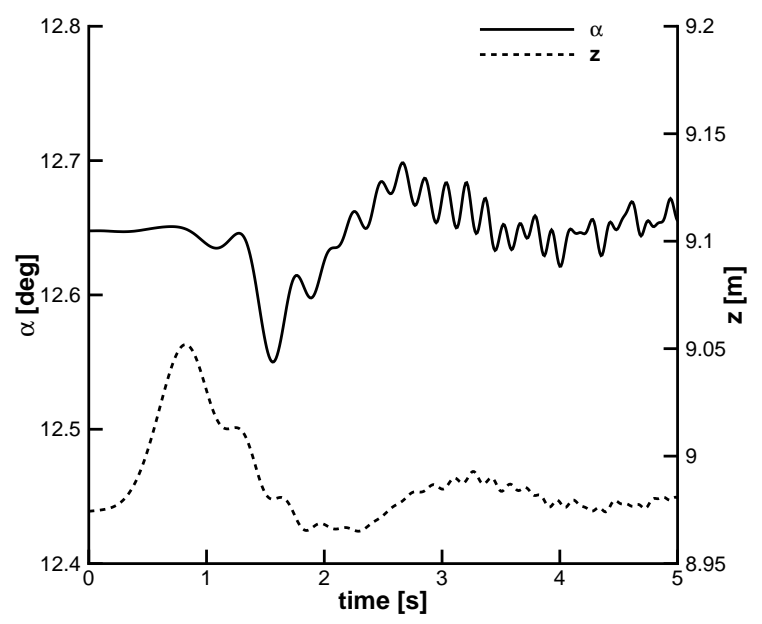

(b) Aircraft AoA and wing tip displacement

Figure 15: Aircraft AoA and wing tip responses with respect to chirp input of aileron
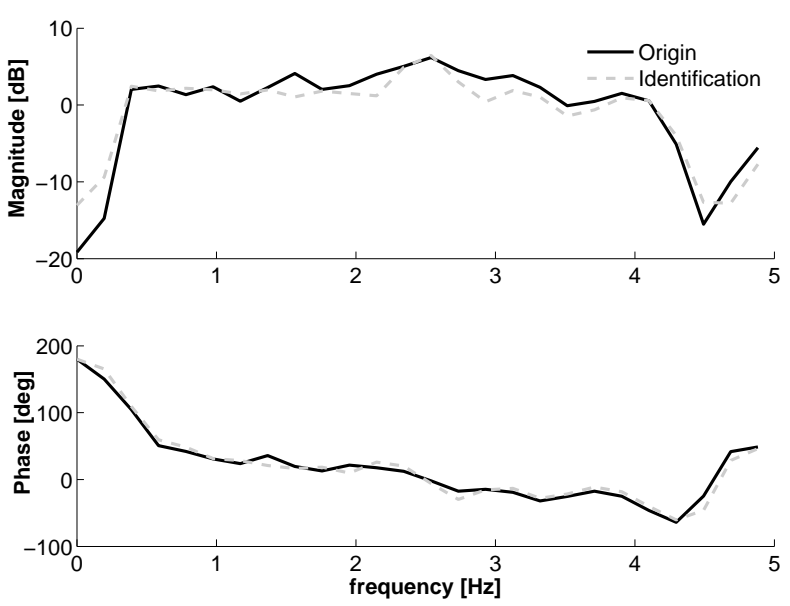

(a) Frequency domain

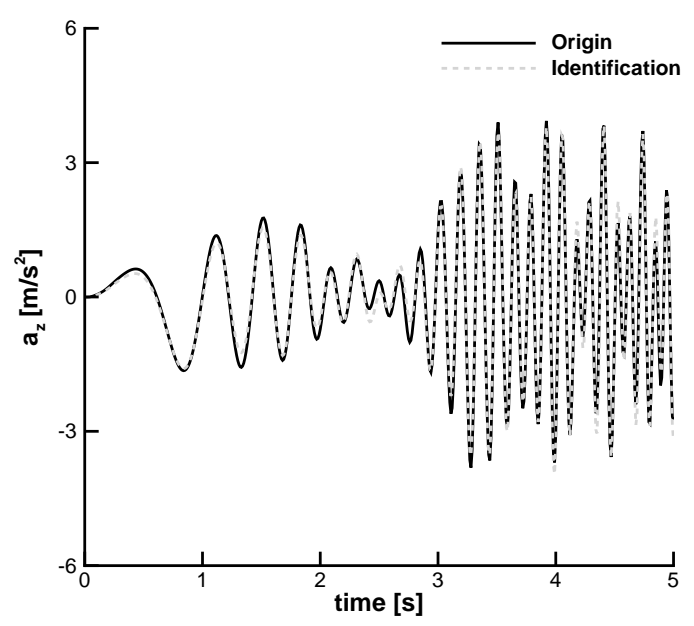

(b) Time domain

Figure 16: The identification results of wing tip acceleration: (a) Bode plot, (b) response in time domain 


\section{Gust Loads Alleviation by Using AFFC}

To show the performance of AFFC, direct adaptive feedback control (AFBC) ${ }^{29}$ of the flexible aircraft is performed. Both "one-minus-cosine" gust and Von Kármán turbulence gust are considered.

\section{1. "One-minus-cosine" Gust}

A "one-minus-cosine" gust with intensity of $1 \mathrm{~m} / \mathrm{s}$ and length of $50 \mathrm{~m}$ is chosen as test case. The open loop and controlled wing tip accelerations and the corresponding aileron deflections by using AFFC and AFBC are shown in Fig 17. The AFFC controller order is 20. The central controller of AFBC is computed by poles placement. The poles chosen for closed loop transfer function are $0.7824 \pm 0.1326 i$, which are corresponding to a second order system with damping ratio of 0.8 and natural frequency of $4.58 \mathrm{~Hz}$. Both AFFC and

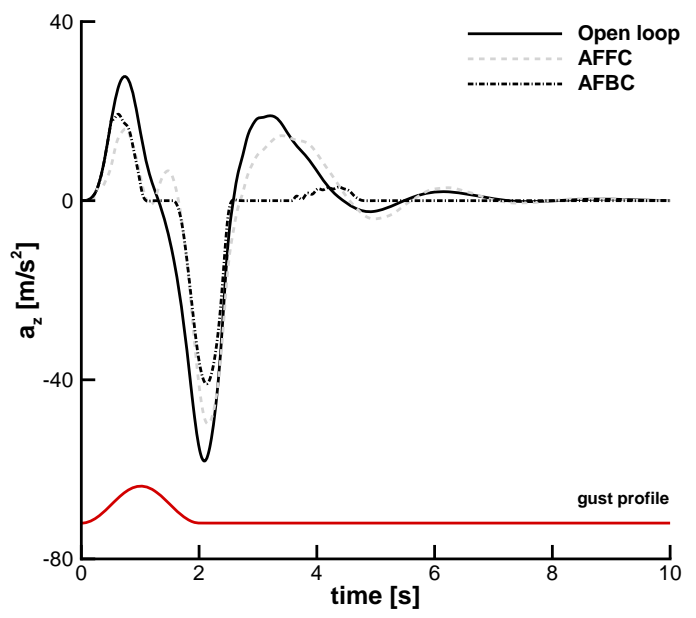

(a) Dynamic responses

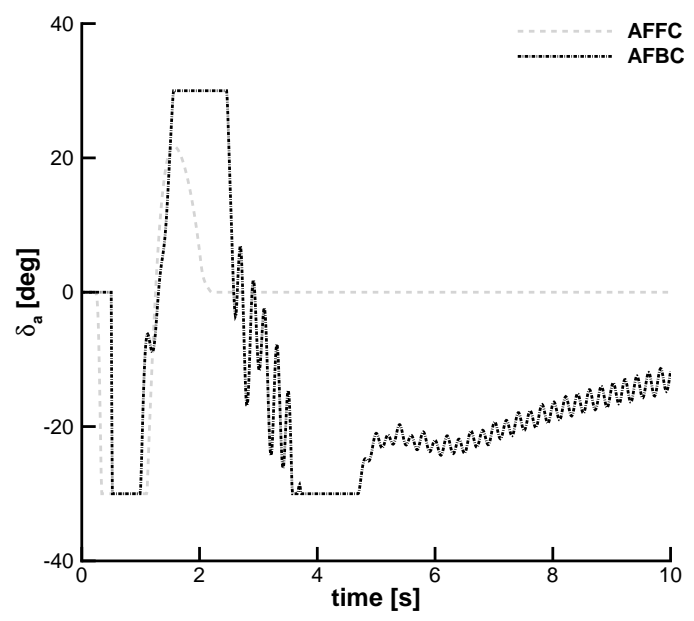

(b) Aileron deflection

Figure 17: Open loop and controlled wing tip accelerations to "one-minus-cosine" gust $\left(w_{g 0}=1 \mathrm{~m} / \mathrm{s}\right.$, $L_{g}=50 \mathrm{~m}, h=20,000 \mathrm{~m}, U_{\infty}=25 \mathrm{~m} / \mathrm{s}$ ) and the corresponding aileron deflections

AFBC controller can alleviate the gust loads of the wing. The AFFC controller shows better performance at the peak, and the magnitude of the wing tip acceleration is reduced by around $40 \%$. The reason is that the AFFC controller compensate the wing response earlier than the AFBC one, especially at the initial stage. The total control effect of the AFBC controller is more outstanding because the control efficiency of AFBC controller is dependent on the poles chosen for the closed loop transfer function.

The AFFC controller uses the gust as reference input, which influences the alleviation effect. The "oneminus-cosine" gust just has one cycle. The input for the AFFC controller will become zero after one cycle of the gust. While the AFBC controller is fed by the wing tip acceleration, which is a continuous signal. This phenomenon can be verified by the aileron deflections in Fig 17b. The aileron deflections are limited by prescribed threshold \pm 30 degree, which decrease the gust loads alleviation effect. It also shows that the controller has reached work saturation state, which means that the aileron surface aera is not enough for this aircraft when encountering the "one-minus-cosine" gust with intensity of $1 \mathrm{~m} / \mathrm{s}$.

\section{Von Kármán Turbulence Gust}

A moderate Von Kármán turbulence gust in vertical direction at altitude of 20,000 m and freestream speed of $25 \mathrm{~m} / \mathrm{s}$ was generated by VKTG code. The time history of this gust is shown in Fig. 18. The corresponding spectrum has been given in Fig. 3. Figure 19 gives the time and frequency domain of the open loop and control responses of wing tip acceleration to this Von Kármán turbulence gust by using AFFC and AFBC controllers. The responses in frequency domain are obtained by fast Fourier transformation (FFT). Similar control effect to "one-minus-cosine" gust is found here again. The time domain responses show that gust 
loads are alleviated by both the AFFC and AFBC controllers. The mean value and standard deviation of the wing tip acceleration are given in Table 7 . The standard deviation of the wing tip acceleration is reduced from $3.1099 \mathrm{~m} / \mathrm{s}^{2}$ to $1.3850 \mathrm{~m} / \mathrm{s}^{2}$ by $55.4 \%$ for the AFFC controller and to $0.3881 \mathrm{~m} / \mathrm{s}^{2}$ by $87.5 \%$ for the AFBC controller, respectively. The aileron defections are presented in Fig. 20. The standard deviation of aileron deflections for the AFFC and AFBC controllers are $2.4709 \mathrm{deg}$ and $4.9044 \mathrm{deg}$, respectively. The AFBC controller obtains better gust loads alleviation effect than the AFFC controller through larger aileron input, which can be found from the time and frequency responses and the corresponding aileron deflections. This is attributed to the pole placement control method used to design the central controller of AFBC. The closed loop transfer function is the same as that of the above "one-minus-cosine" gust case. Figure 19b also exhibits that the AFBC controller has a broader control band than the AFFC controller in this case.

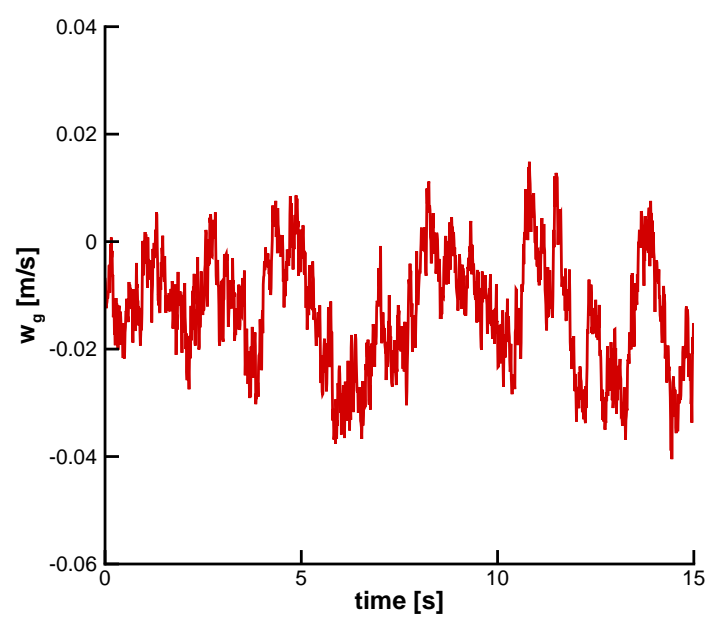

Figure 18: A Von Kármán gust $\left(h=20,000 \mathrm{~m}\right.$, intensity $=10^{-3}$, 'moderate', $\left.U_{\infty}=25 \mathrm{~m} / \mathrm{s}\right)$; for spectrum, see Fig. 3

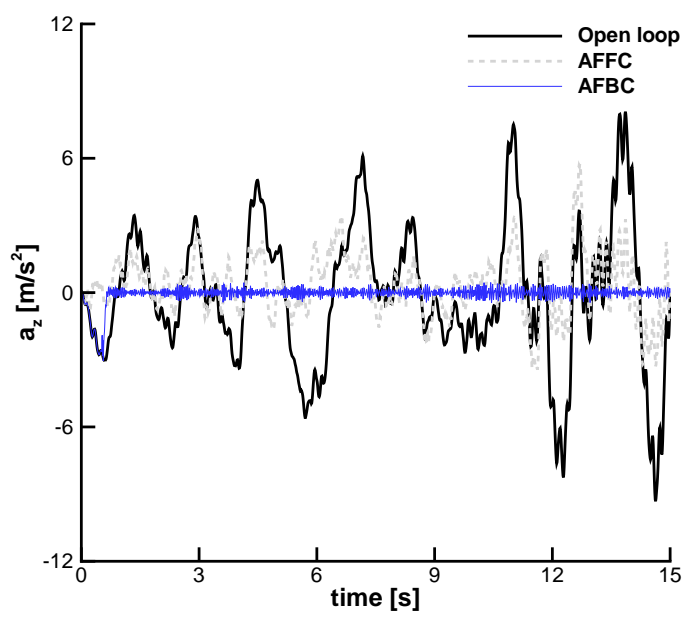

(a) Time domain

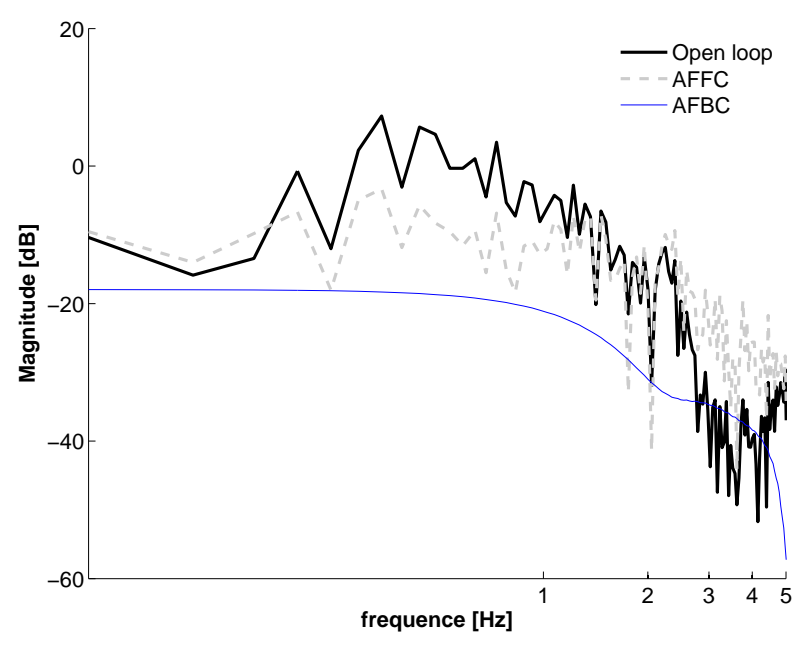

(b) Frequency domain

Figure 19: Open loop and controlled wing tip accelerations to a moderate Von Kármán turbulence gust $\left(h=20,000 \mathrm{~m}\right.$, intensity $=10^{-3}$, 'moderate', $\left.U_{\infty}=25 \mathrm{~m} / \mathrm{s}\right)$ 
Table 7: The mean value and standard deviation of wing tip acceleration

\begin{tabular}{llll}
\hline \hline & Open loop $\left[\mathrm{m} / \mathrm{s}^{2}\right]$ & AFFC $\left[\mathrm{m} / \mathrm{s}^{2}\right]$ & AFBC $\left[\mathrm{m} / \mathrm{s}^{2}\right]$ \\
\hline Mean value & -0.1096 & 0.3135 & -0.0631 \\
Standard deviation & 3.1099 & 1.3850 & 0.3881 \\
\hline \hline
\end{tabular}

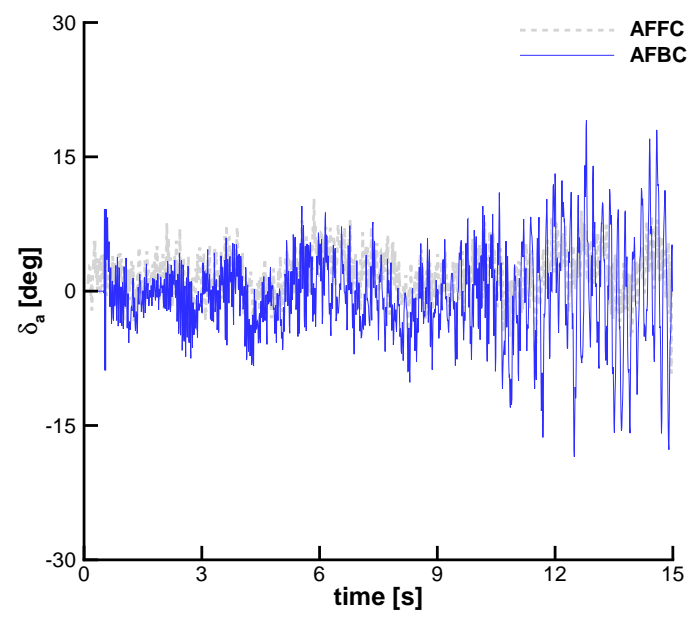

Figure 20: Aileron deflections of AFFC and AFBC to a moderate Von Kármán turbulence gust $(h=20,000$ $\mathrm{m}$, intensity $=10^{-3}$, 'moderate', $U_{\infty}=25 \mathrm{~m} / \mathrm{s}$ )

Another type of control effectiveness index (CEI) is

$$
\mathrm{CEI}=\frac{s t d \_d e v(\text { Open loop response })-s t d \_d e v(\text { Controlled response })}{s t d \_d e v(\text { Control input })}
$$

where std_dev means standard deviation, and the control input here is aileron deflection. The CEI of the AFFC and AFBC controllers are $0.6981\left(\mathrm{~m} / \mathrm{s}^{2}\right) / \mathrm{deg}$ and $0.5550\left(\mathrm{~m} / \mathrm{s}^{2}\right) / \mathrm{deg}$, respectively. The control effectiveness of the AFBC controller is higher than the AFFC controller if using CEI as index.

\section{Conclusion}

Gust loads alleviation using adaptive feedforward control was investigated. Finite impulse response model was used to design the controller. Robustness was strengthened by an adaptive strategy. Two plants were presented, one for an aerofoil aeroelastic system, the other for a highly flexible aircraft. Structural nonlinearities were modeled in polynomial form for the aerofoil system, and in the geometrically exact nonlinear beam formulation for the aircraft configuration. A framework integrated aerodynamics-structureflight dynamics was built to the flexible HALE aircraft. Strip theory assumption and two-dimensional Theodorsen theory were used in the unsteady aerodynamic model. Trim of the aircraft was performed first to obtain the baseline state. Then all the dynamic responses were calculated from this state. Both discrete and continuous turbulence gusts were studied. Two control laws were adopted for the aerofoil and the flexible aircraft, respectively.

Through the test cases, two conclusions can be drawn as follows:

- The adaptive feedforward control can alleviate both the discrete and continuous turbulence gust loads. For "one-minus-cosine" gust, the amplitude of the open loop response is reduced at the initial several cycles, and the first peak value reduction is more than $40 \%$. For Von Kármán turbulence gust, both the standard deviation and mean value are reduced. The reduction of standard deviation is more than $35 \%$. 
- Comparing to adaptive feedback control, the adaptive feedforward control shows better potential at the beginning stage of the two types of gust. If using standard deviation as index, the adaptive feedback controller obtains better gust loads alleviation effect than the adaptive feedforward controller through larger aileron deflections. When using CEI as index, the control effectiveness of adaptive feedback control is also higher than adaptive feedforward control.

Future work will focus on increasing the control effectiveness of adaptive feedforward controllers, e.g., using generalized orthonormal finite impulse response model basis to design the controller. The combination of adaptive feedforward control with adaptive feedback control or robust feedback control is also an effective approach to increase the gust loads alleviation efficiency. Another ongoing work is using wind tunnel experiment or flight test to verify these controllers.

\section{Acknowledgments}

The "Fast Nonlinear Aeroelastic Search for Loads Assessment" was supported by the Royal Academy of Engineering under the Newton Research Collaboration Programme.

\section{References}

\footnotetext{
${ }^{1}$ Noll, T. E., Brown, J. M., Perez-Davis, M. E., Ishmael, S. D., Tiffany, G. C., and Gaier, M., "Investigation of the Helios Prototype Aircraft Mishap," 2004.

${ }^{2}$ Patil, M. J., "Nonlinear Gust Response of Highly Flexible Aircraft," 48th AIAA/ASMe/ASCE/AHS/SC Structures, Structural Dynamics, and Materials Conference, Honolulu, Hawaii, 11-15 April 2007.

${ }^{3}$ Karpel, M., "Design for Active Flutter Suppression and Gust Alleviation Using State-Space Aeroelastic Modeling," Journal of Aircraft, Vol. 19, No. 3, 1982, pp. 221-227, doi: 10.2514/3.57379.

${ }^{4}$ Block, J. J. and Strganac, T. W., "Applied Active Control for a Nonlinear Aeroelastic Structure," Journal of Guidance, Control, and Dynamics, Vol. 21, No. 6, 1998, pp. 838-845, doi: 10.2514/2.4346.

${ }^{5}$ Vipperman, J. S., Clark, R. L., Conner, M., and Dowell, E. H., "Experimental Active Control of a Typical Section Using a Trailing-Edge Flap," Journal of Aircraft, Vol. 35, No. 2, 1998, pp. 224-229, doi: 10.2514/2.2312.

${ }^{6}$ Palumbo, D., Cabell, R., Cline, J., and Sullivan, B., "Active Structural Acoustic Control of Interior Noise on a Ratheon 1900D," Nasa/tm-2000-209846 arl-tr-2205, 2000

${ }^{7}$ Zimcik, D. G., "Active Control of Aircraft Cabin Noise," RTO AVT Symposium on Habitability of Combat and Transport Vehicles:Noise, Vibration and Motion, RTO-MP-AVT-110, Prague, Czech Republic, 4-7 October 2004.

${ }^{8}$ Da Ronch, A., Tantaroudas, N. D., and Badcock, K. J., "Reduction of Nonlinear Models for Control Applications," 54th AIAA/ASME/ASCE/AHS/ASC Structures, Structural Dynamics, and Materials Conference, AIAA Paper 2013-1491, Boston, MA, 08-11 April 2013, doi: 10.2514/6.2013-1491.

${ }^{9}$ Brosilow, C. and Joseph, B., Techniques of Model-based Control, chap. 9, Prentice Hall PTR, 1st ed., 2002, p. 222.

${ }^{10} \mathrm{Hahn}, \mathrm{K} .-\mathrm{U}$. and Schwarz, C., "Alleviation of Atmospheric Flow Disturbance Effects on Aircraft Response," 26th Congress of the International Council of the Aeronautical Sciences, ICAS 2008, Anchorage, Alaska, USA, 14-19 September 2008.

${ }^{11}$ Soreide, D., Bogue, R. K., Ehernberger, L. J., and Bagley, H., "Coherent Lidar Turbulence Measurement for Gust Load Alleviation," Nasa technical memorandum 104318, 1996.

${ }^{12}$ Schmitt, D., Rehm, W., Pistner, T., Diehl, H., Navé, P., Jenaro-Rabadan, G., Mirand, P., and Reymond, M., "Flight Test of the AWIATOR Airborne LIDAR Turbulence Sensor," 14th Coherent Laser Radar Conference, Hunstvile, AL, June 2007.

${ }^{13}$ Inokuchi, H., Tanaka, H., and Ando, T., "Development of an Onboard Doppler LIDAR for Flight Safety," 26th Congress of the International Council of the Aeronautical Sciences, ICAS 2008, Anchorage, Alaska, USA, 14-19 September 2008.

${ }^{14}$ Reitebush, O., Lemmerz, C., Nagel, E., Paffrath, U., Durand, Y., Endemann, M., Fabre, F., and Chanloupy, M., "The Airborne Demonstrator for the Direct-Detection Doppler Wind Lidar ALADIN on ADM-Aeolus. Part I: Instrument Design and Comparison to Satellite Instrument," Journal of Atmospheric and Oceanic Techonology, Vol. 26, 2009, pp. 2501-2515, doi: 10.1175/2009JTECHA1309.1.

${ }^{15}$ Inokuchi, H., Furuta, M., and Inagaki, T., "High Alitude Turbulence Detection Using an Airborne Doppler LIDAR," 29th Congress of the International Council of the Aeronautical Sciences, ICAS 2014, St, Petersburg, Russia, 07-12 September 2014.

${ }^{16}$ Regan, C. D. and Jutte, C. V., "Survey of Applications of Active Control Technology for Gust Alleviation and New Challenges for Lighter-weight Aircraft," Nasa/tm2012216008, 2012.

${ }^{17}$ Zeng, J., Moulin, B., De Callafon, R., and Brenner, M., "Adaptive Feedforward Control for Gust Load Alleviation," Journal of Guidance, Control, and Dynamics, Vol. 33, No. 3, 2010, pp. 862-872, doi: 10.2514/1.46091.

${ }^{18}$ Da Ronch, A., Badcock, K. J., Wang, Y., Wynn, A., and Palacios, R. N., "Nonlinear Model Reduction for Flexible Aircraft Control Design," AIAA Atmospheric Flight Mechanics Conference, AIAA Paper 2012-4404, Minneapolis, MN, 13-16 August 2012, doi: 10.2514/6.2012-4404.

${ }^{19}$ Wildschek, A. and Maier, R., "Integrated Adaptive Feed-forward Control of Atmospheric Turbulence excited Rigid Body Motions and Structural Vibrations," 2008 American Control Conference, Seattle, Washington, USA, 11-13 June 2008.
} 
${ }^{20}$ Wildschek, A., Maier, R., Hahn, K.-U., Lei $\beta$ ling, D., Pre $\beta$, M., and Zach, A., "Flight Test with an Adaptive FeedForward Controller for Alleviation of Turbulence Excited Wing Bending Vibrations," AIAA Guidance, Navigation, and Control Conference, Chicago, Illinois, 10-13 August 2009.

${ }^{21}$ Wang, Y., Da Ronch, A., Ghandchi Tehrani, M., and Li, F., "Adaptive feedforward control design for gust loads alleviation and LCO suppression," 29th Congress of the International Council of the Aeronautical Sciences, ICAS 2014, St, Petersburg, Russia, 07-12 September 2014, doi: 10.13140/2.1.4464.2566.

${ }^{22}$ Da Ronch, A., Tantaroudas, N., and Jiffri, S.and Mottershead, J., "A Nonlinear Controller for Flutter Suppression: from Simulation to Wind Tunnel Testing," 55th AIAA/ASMe/ASCE/AHS/SC Structures, Structural Dynamics, and Materials Conference, AIAA SciTech 2014, National Harbor, MD, 11-15 January 2014, doi: 10.2514/6.2014-0345.

${ }^{23}$ Hesse, H., Murua, J., and Palacios, R., "Consistent Structural Linearization in Flexible Aircraft Dynamics with Large Rigid-Body Motion," 53rd AIAA/ASME/ASCE/AHS/ASC Structures, Structural Dynamics and Materials Conference.

${ }^{24}$ Tantaroudas, N. D., Da Ronch, A., Badcock, K. J., and Palacios, R., "Model Order Reduction for Control Design of Flexible Free-Flying Aircraft," AIAA Atmospheric Flight Mechanics Conference, AIAA-2015-0240, Kissimmee, FL, 05-09 January 2015.

${ }^{25}$ Haykin, S., Adaptive Filter Theory, chap. 13, Prentice Hall Information and System Science series, 3rd ed., 2001, pp. $566-569$.

${ }^{26}$ Alam, M., Hromcik, M., and Hanis, T., "Active gust load alleviation system for flexible aircraft: Mixed feedforward/feedback approach," Aerospace Science and Technology, Vol. 41, 2015, pp. 122-133, doi: http://dx.doi.org/10.1016/j.ast.2014.12.020.

${ }^{27}$ Da Ronch, A., Tantaroudas, N. D., Timme, S., and Badcock, K. J., "Model reduction for linear and nonlinear gust loads analysis," 54th AIAA/ASME/ASCE/AHS/ASC Structures, Structural Dynamics, and Materials Conference, Boston, U.S.A, 08-11 April 2013, doi: 10.2514/6.2013-1492.

${ }^{28}$ Murua, J., Flexible Aircraft Dynamics with a Geometrically-Nonlinear Description of the Unsteady Aerodynamics, Ph.D. thesis, Imperial College London, United Kingdom, May 2012.

${ }^{29}$ Landau, I. D., lozano, R., M’Saad, M., and Karimi, A., Adaptive Control, Springer, 2nd ed., 2011, pp. $477-486$. 